Food Under The Microscope

Stephen W. Carmichael, ${ }^{1}$ Mayo Clinic

Carmichael.stephen@mayo.edu

We're all interested in food. Food is the sustenance of life. And you're interested in microscopy, or else you would not be reading this column. So here's a web site that will appeal to both of your interests. ${ }^{2}$ Miloš Kalabb is the author of the web site, and he's enlisted a host of food scientists to assist him. There's no lack of expertise here!

The home page can send you to many locations, but let's begin with the site that deals with microscopy. It is said that the earliest microscopists trained their simple instruments on food, mainly to look for contaminants. We are then treated to a primer on microscopy, beginning with light microscopy, then advancing to electron microscopy. The basic principles of transmission and scanning electron microscopy are explained, with several links to other sites for more details. The environmental scanning electron microscope, that allows the examination of hydrated specimens, is introduced as an instrument for the future in food science. Preparatory techniques, from the routine to the laborious (freeze-fracturing, encapsulation in agar, immunolocalization, etc.), are explained.

Most of the site is dedicated to specific foods, with an apparent emphasis on milk products. Why is milk white? The small $(100 \mathrm{~nm})$ particles of casein and larger fat globules scatter all wavelengths of visible light equally, making milk opaque and white. Higher fat concentrations and dietary intake (food high in carotene for example) can give milk a yellowish tint. You can learn more about the whey proteins $\alpha$-lactalbumin and $\beta$ lactoglobulin than you thought possible. Fresh milk contains lactic acid bacteria and other contaminants, so a discussion of sterilization (pasteurization) is included.

Cheese is made from curdled milk. Details of cheese making are given, along with the microscopic appearance of the product during the various steps. Since each of the parameters

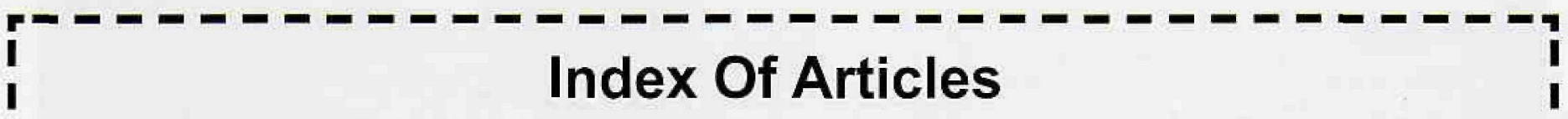

Food Under The Microscope Stephen Carmichael, Mayo Clinic

Some Thoughts On Vibrations In EM Laboratories Anthony J. Garratt-Reed, MIT

I

The Emergence of Aberration Correctors

for Electron Lenses. John Silcox, Comell University

Fast Orientation Imaging Microscopy

D. J. Dingley*, S. Wright and M. Nowell TSL

I (a subsidiary of EDAX)

Fitting a Student Microscope with a Consumer

I Digital Camera. Theodore M. Clarke, Metallurgical F. A. Consultant

Microscopy in the Real World:

A Manufacturer's Perspective

Michael M. Kersker, JEOL USA, Inc.

All That Glitters is not Gold:

Approaches to Labeling for TEM.

R.M. Albrecht and D.A. Meyer, University of Wisconsin

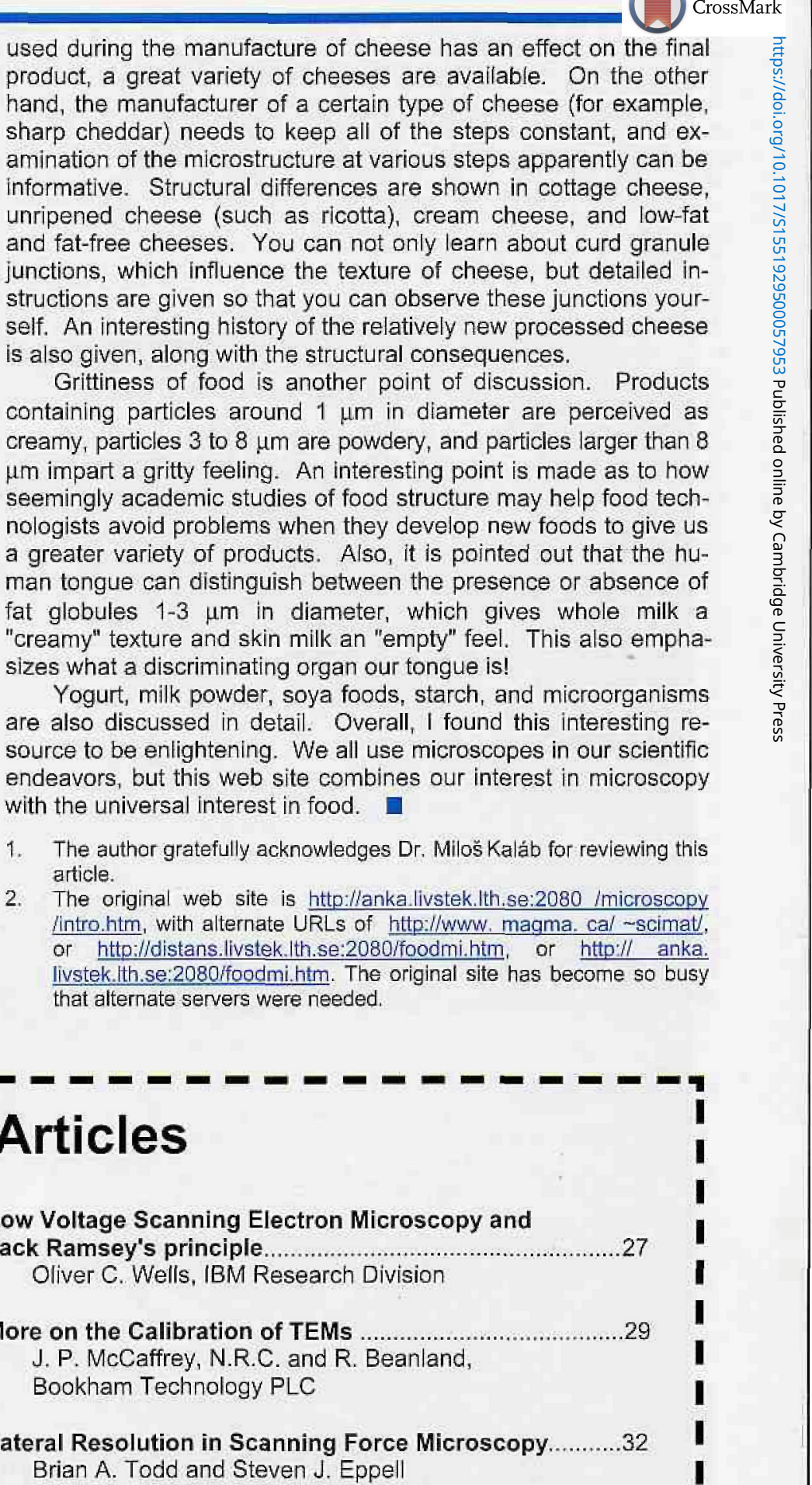

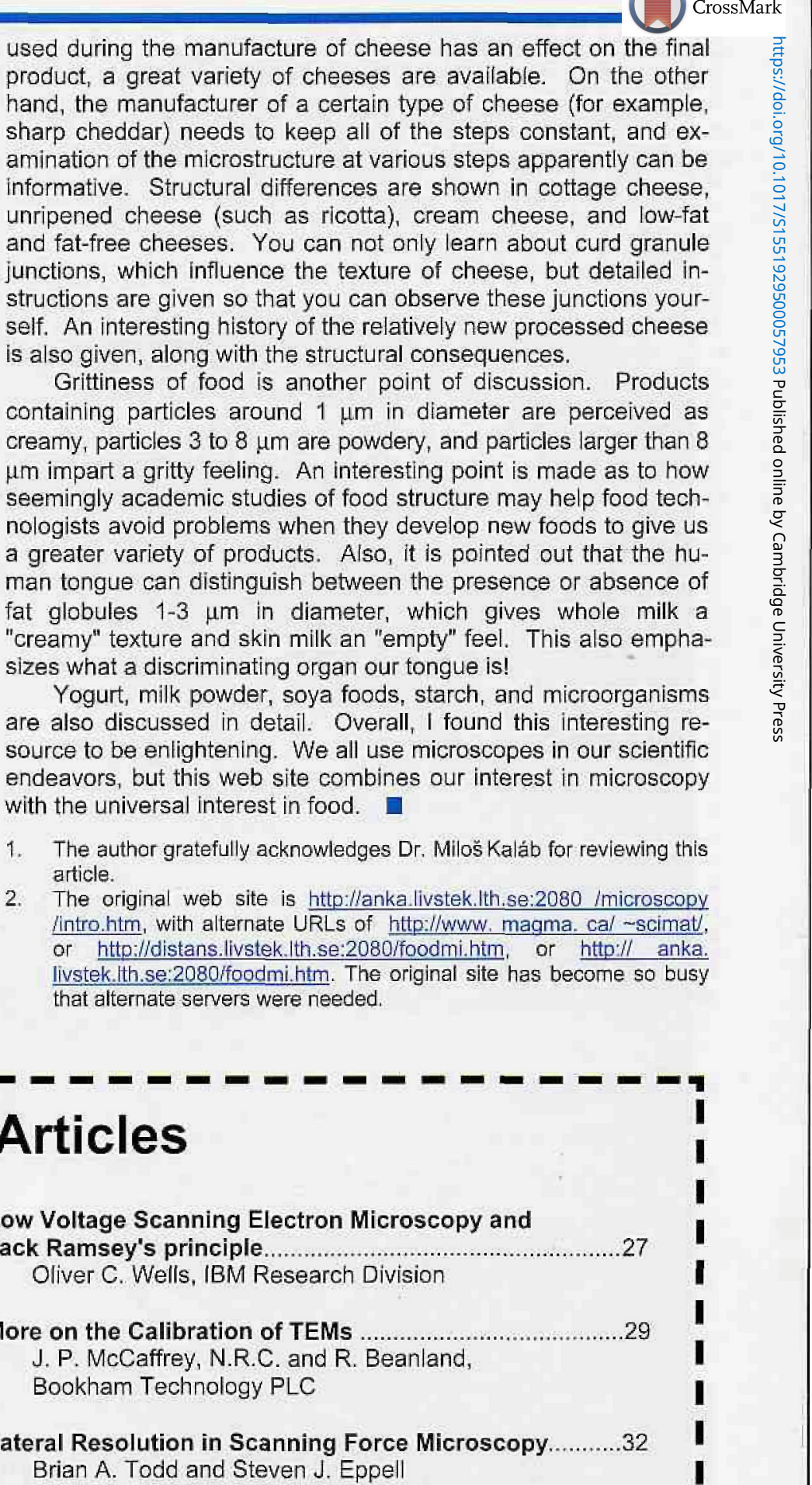

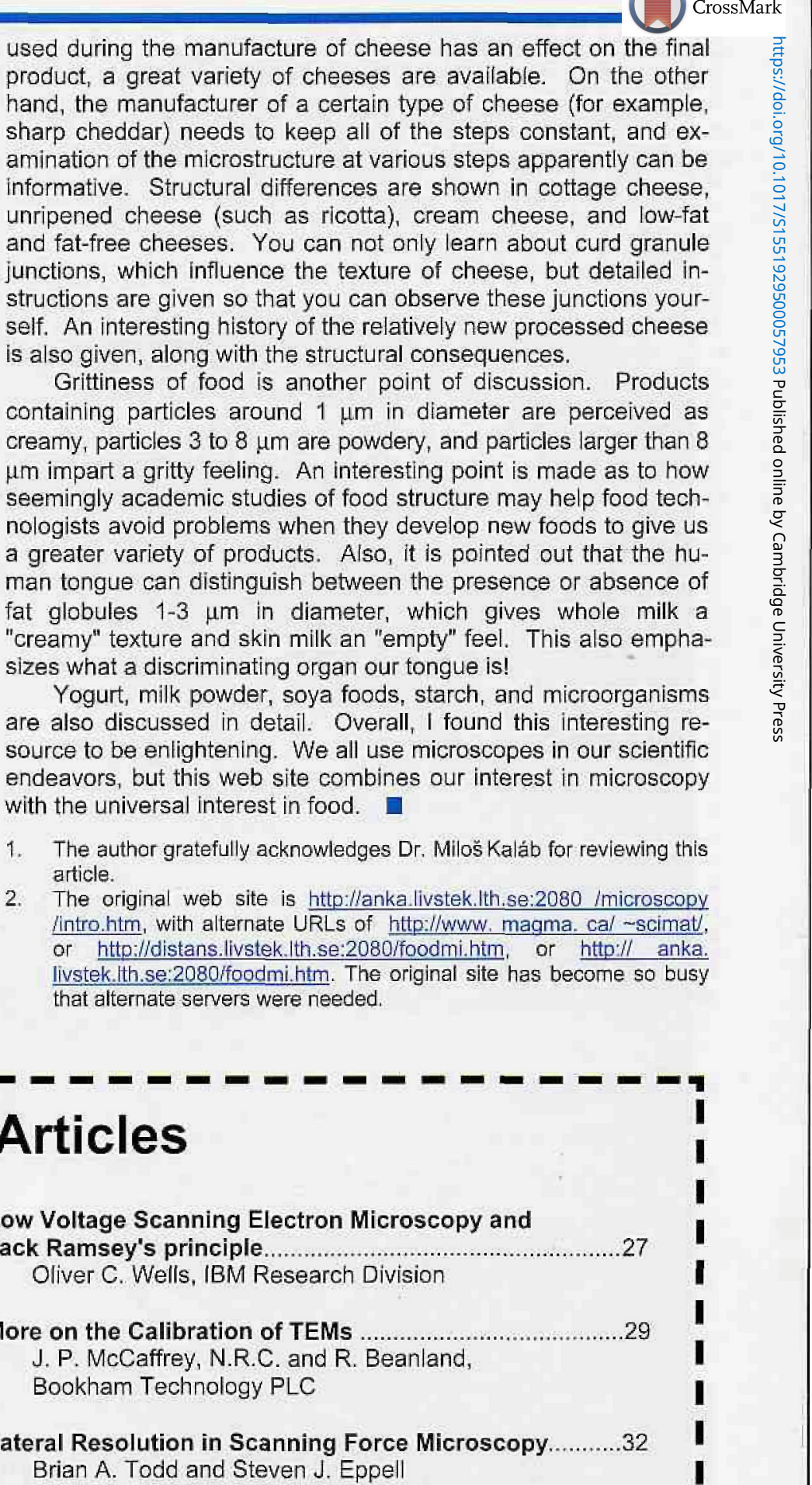

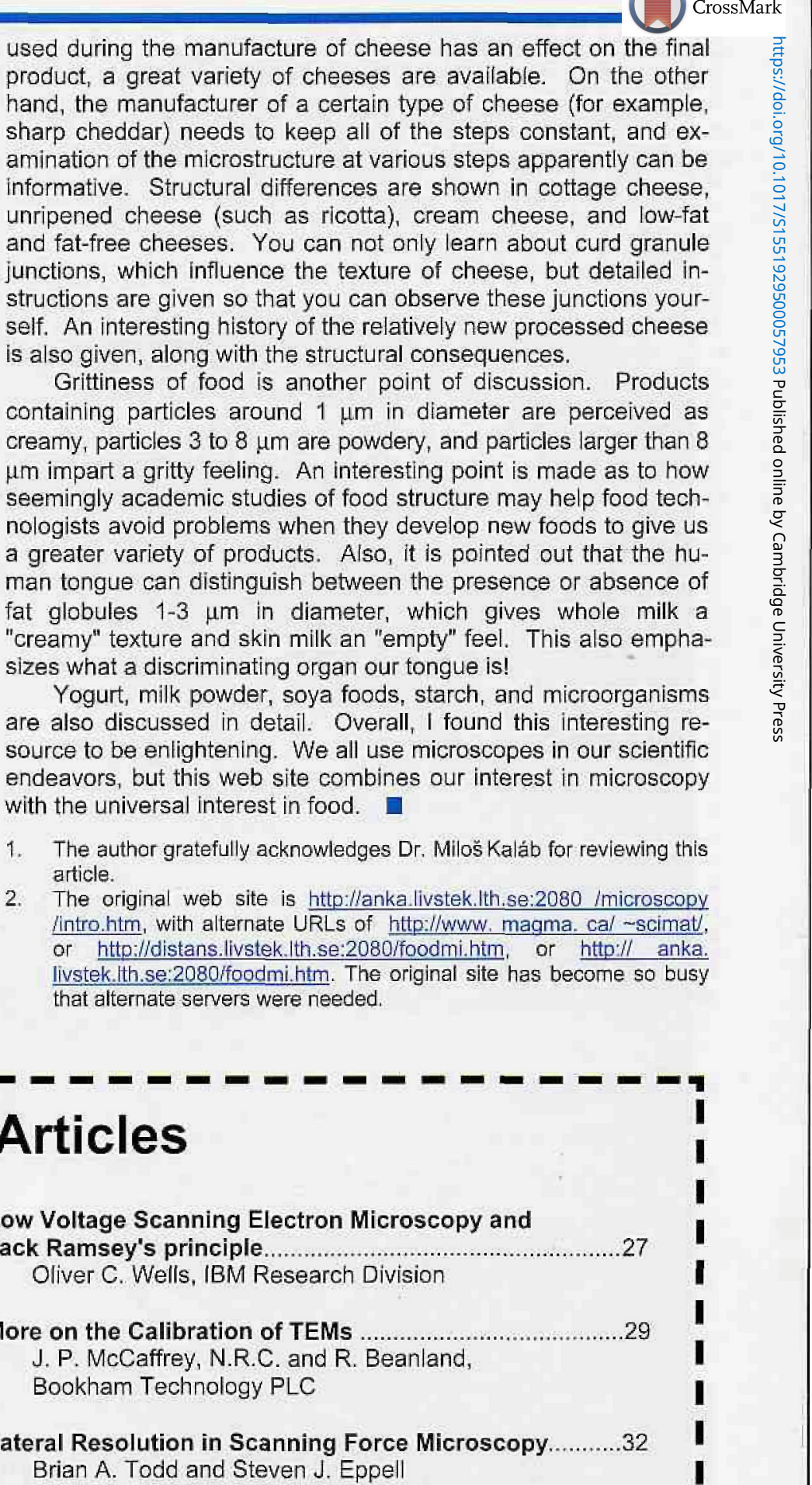

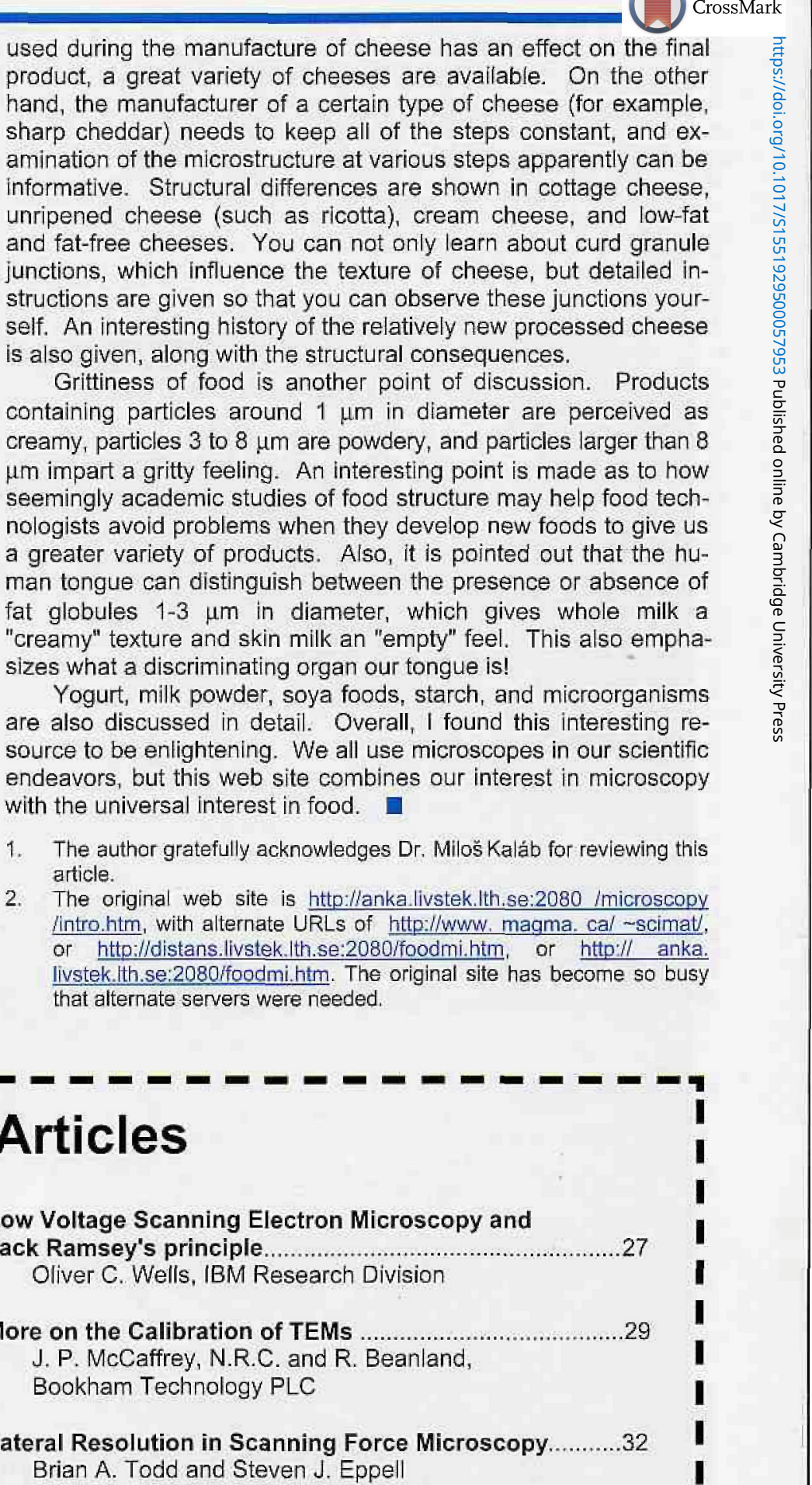

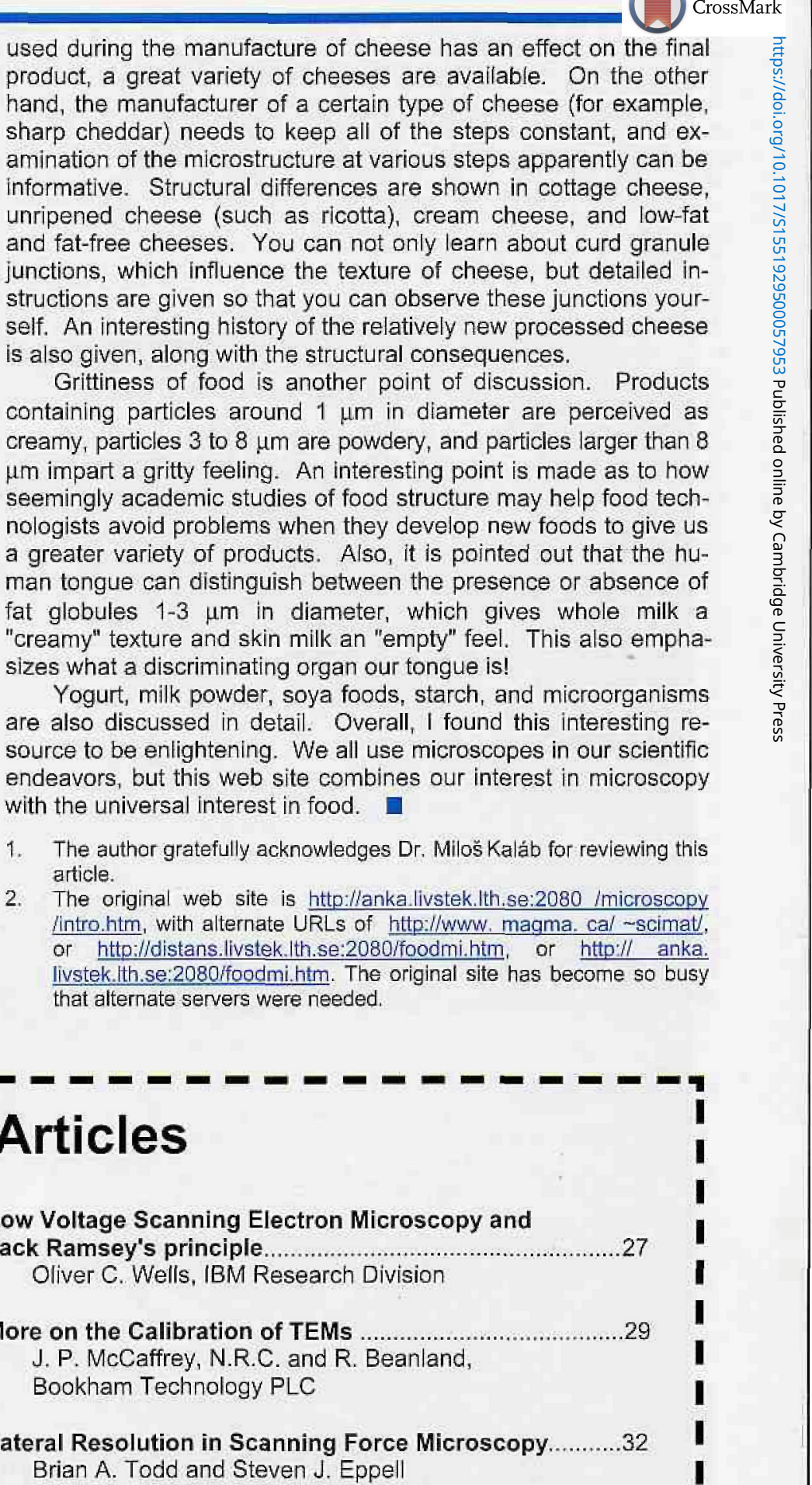

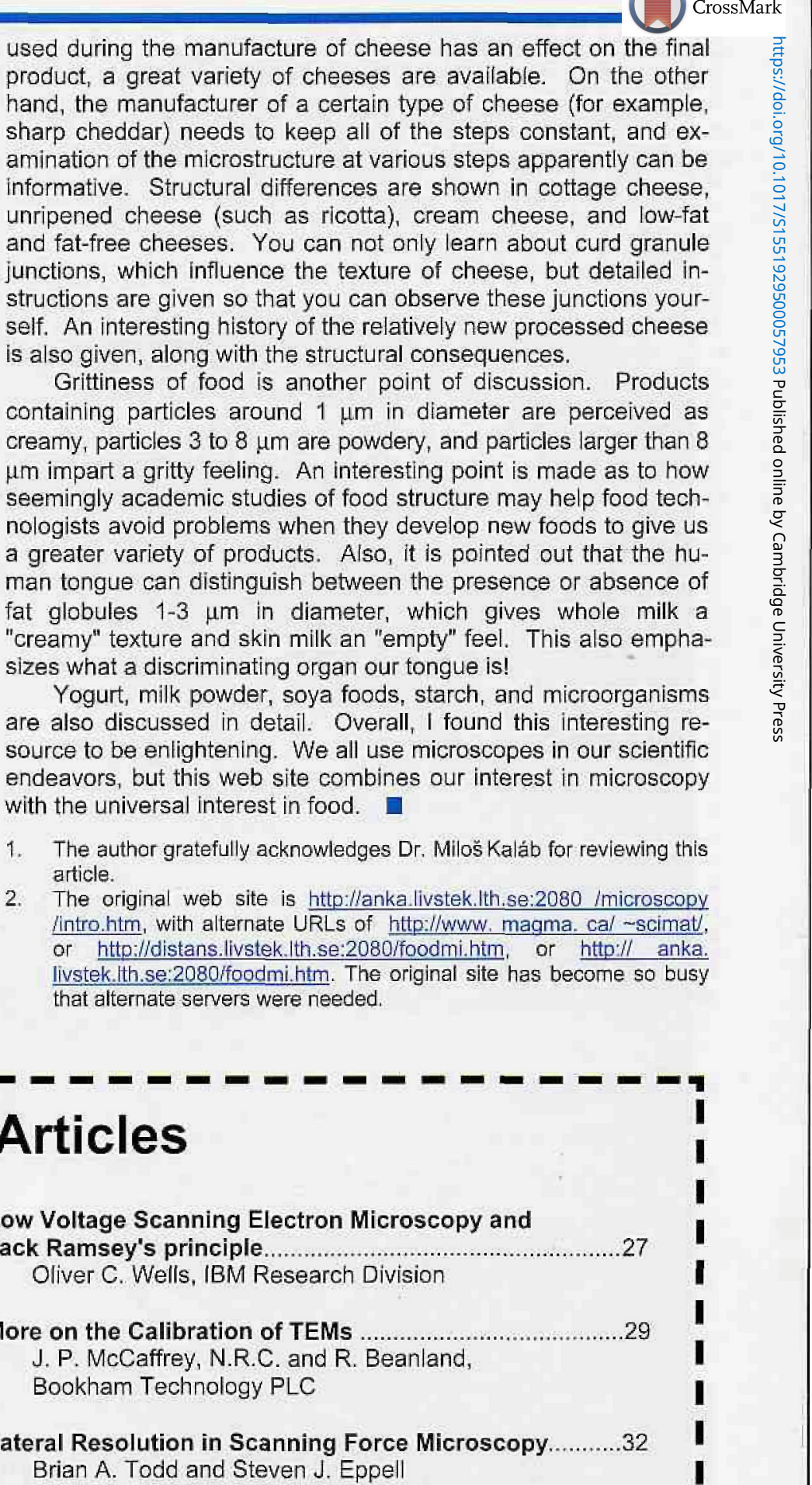

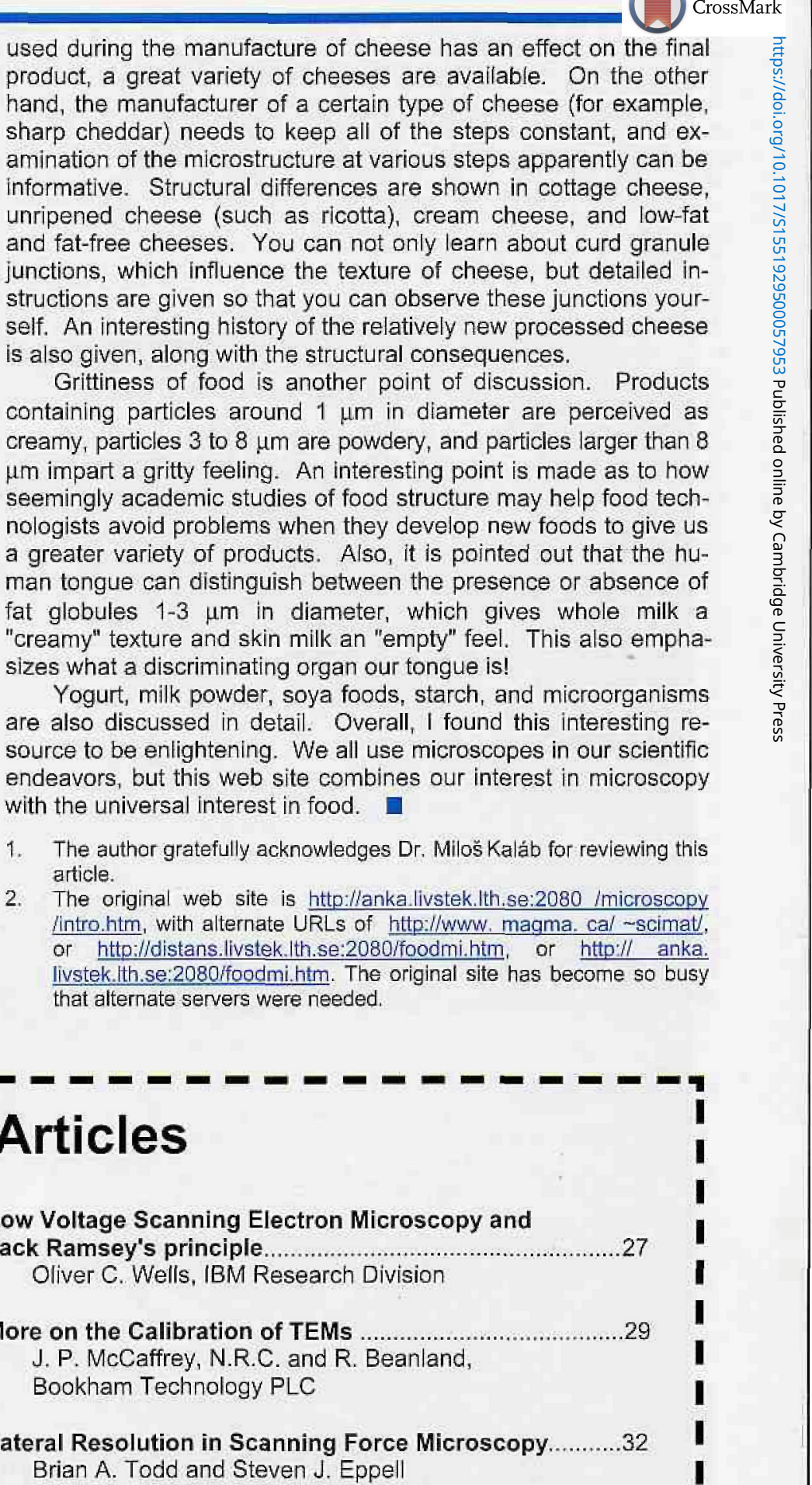

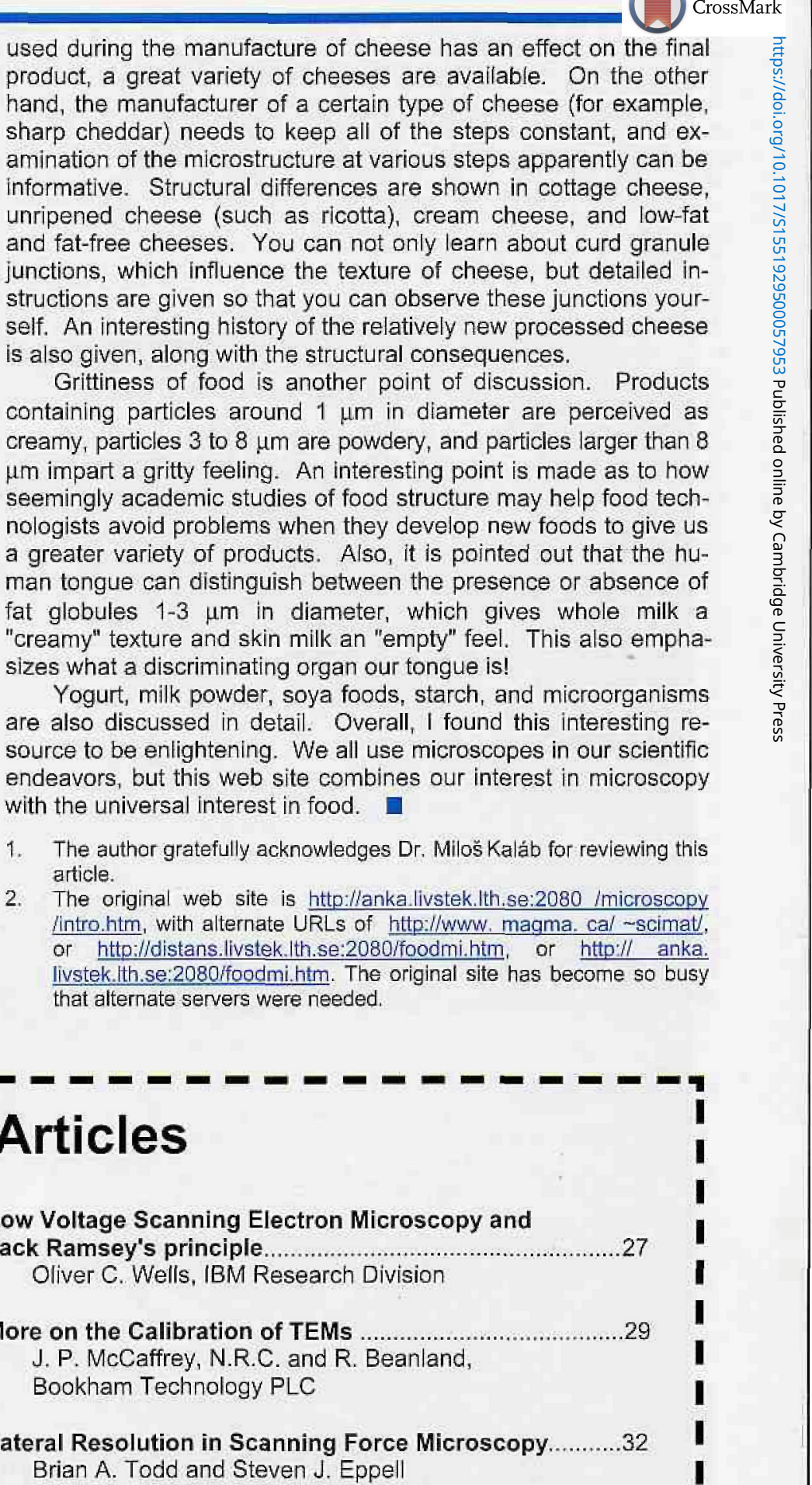

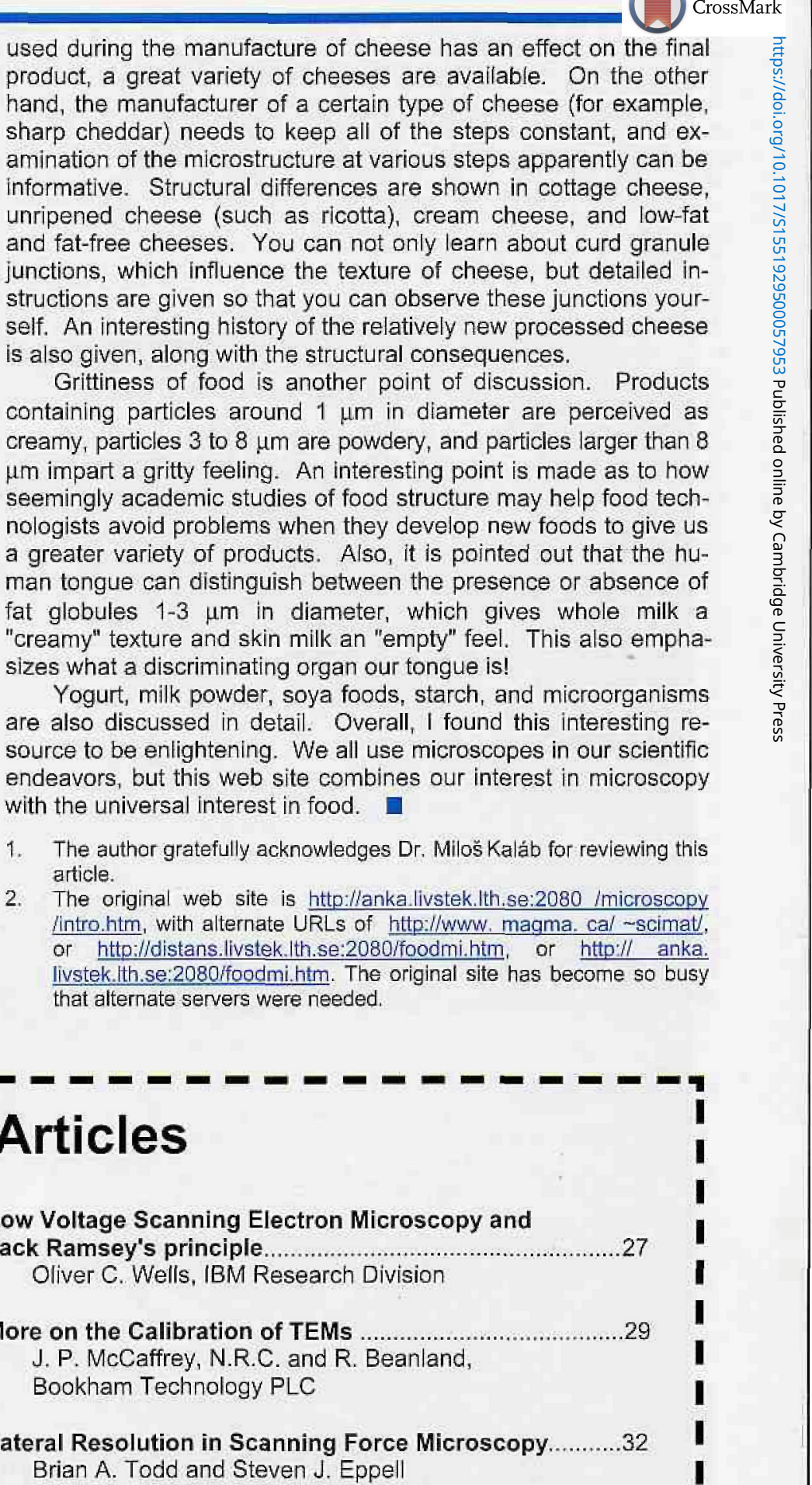

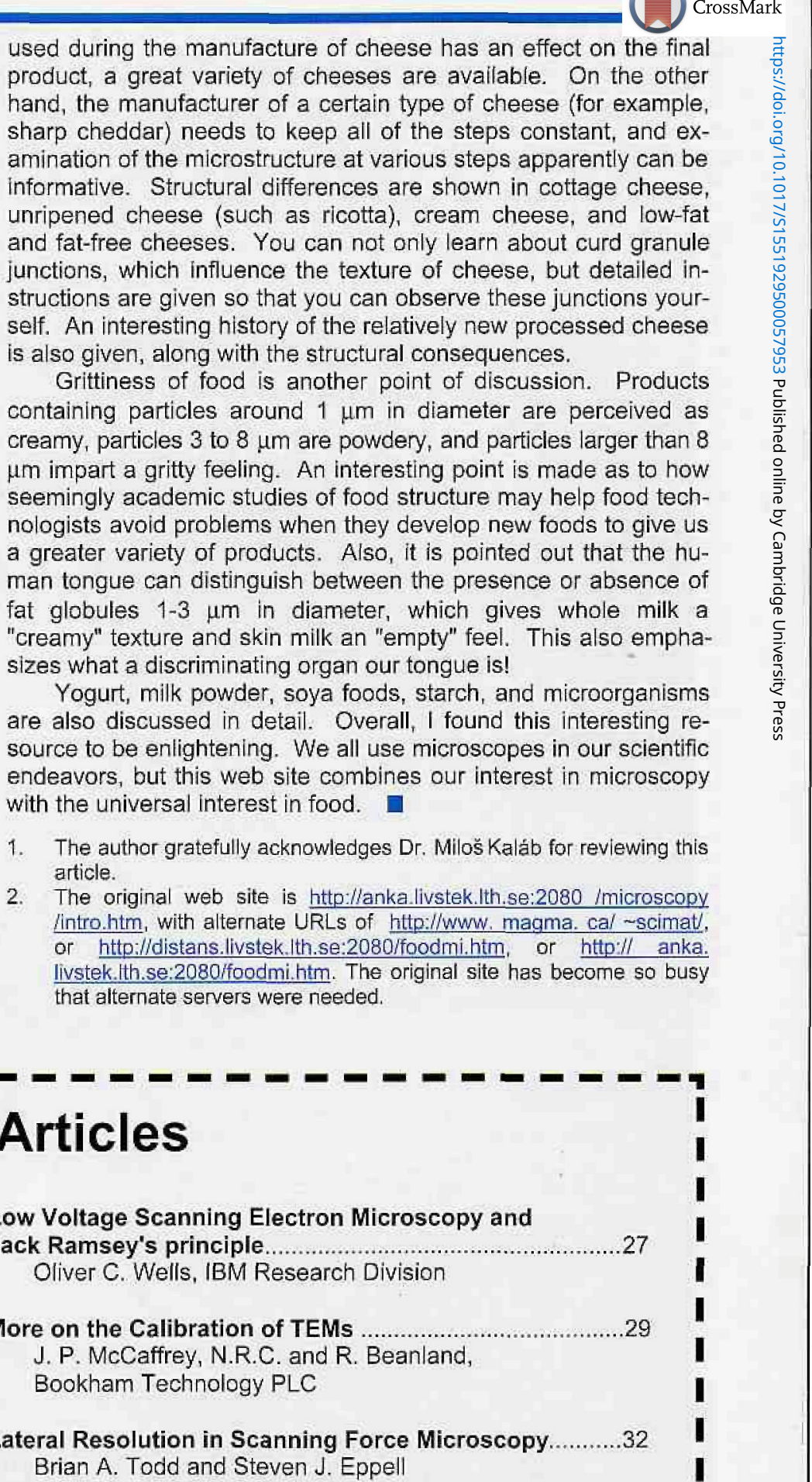

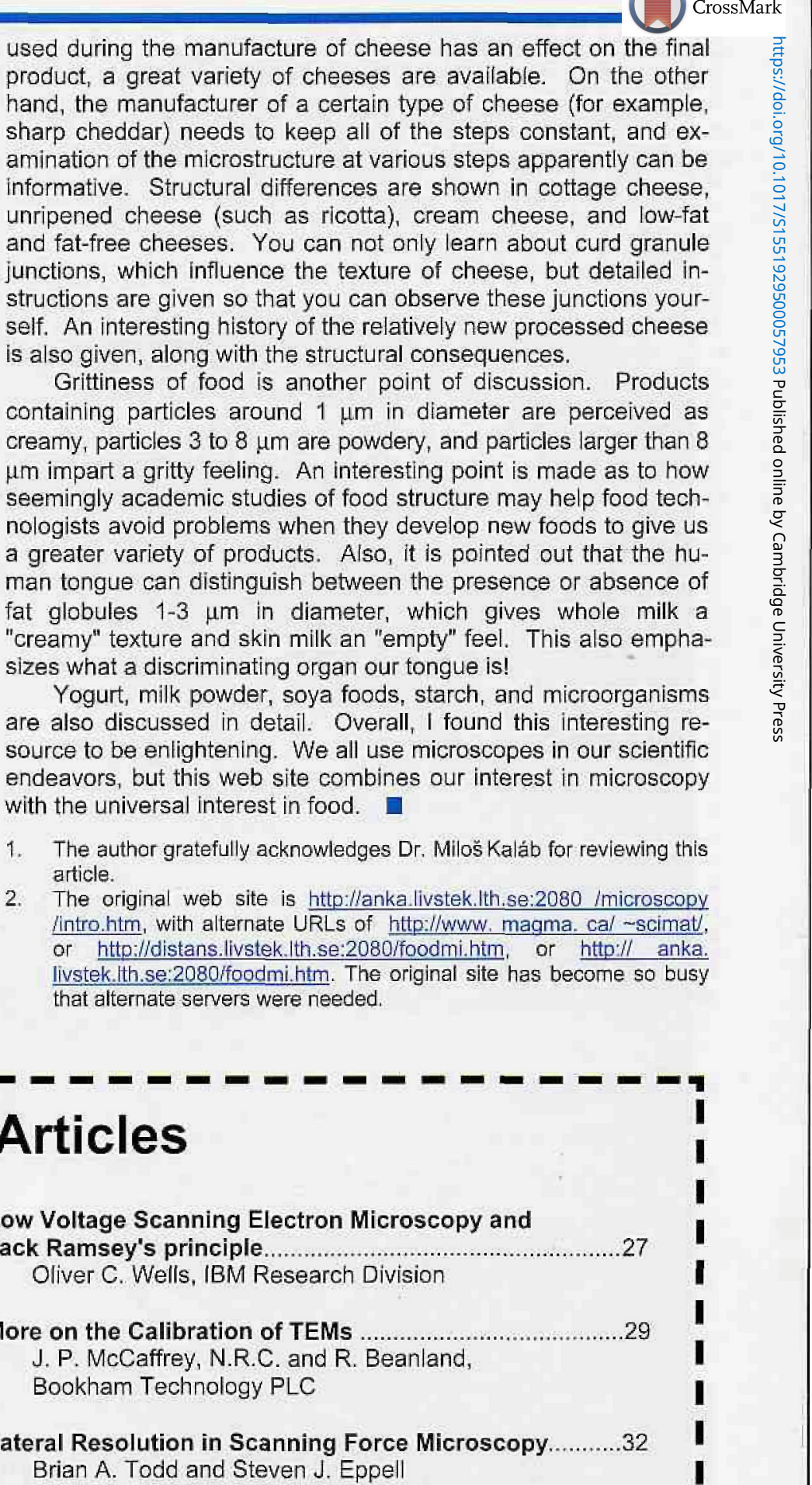

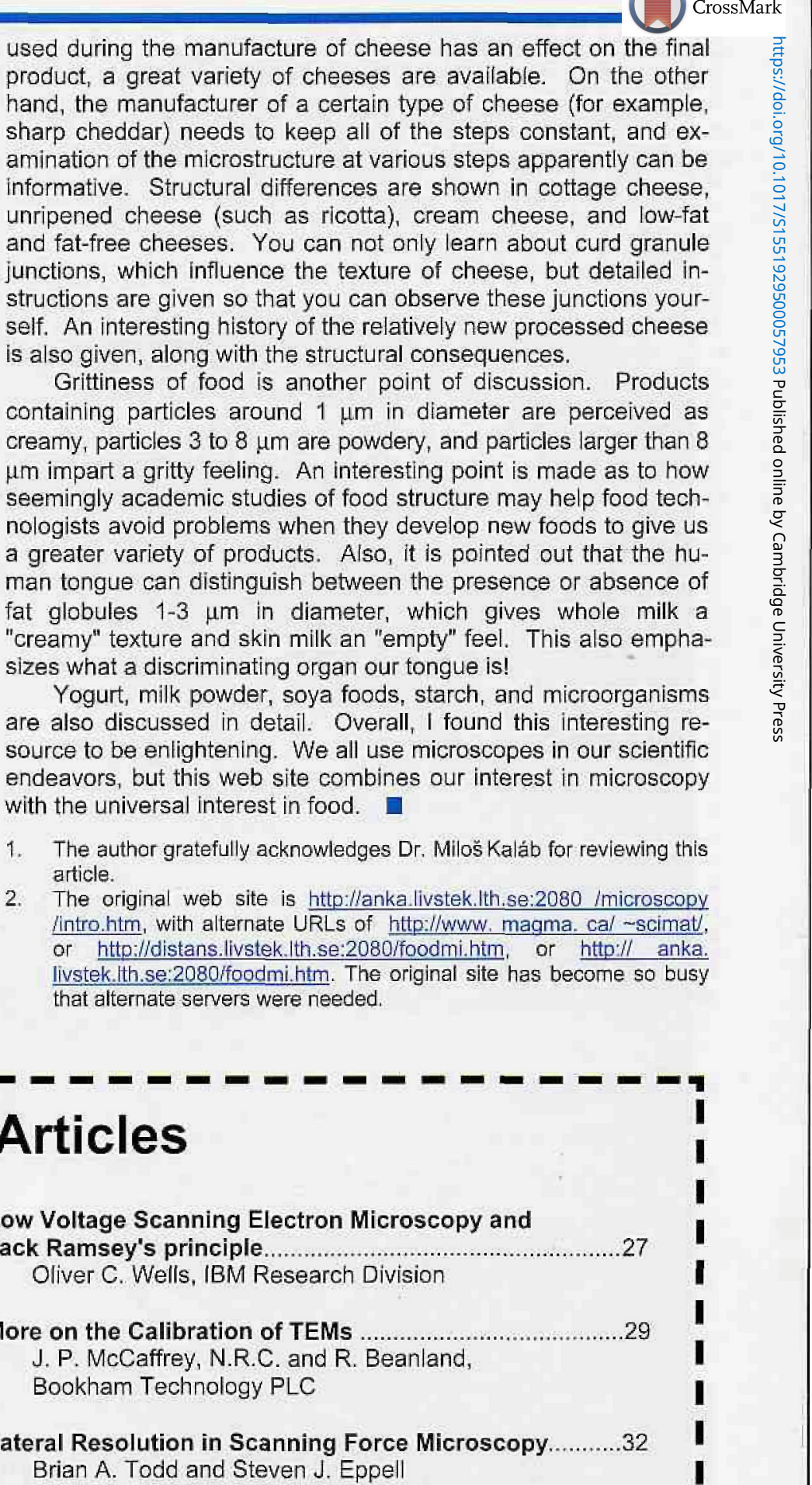

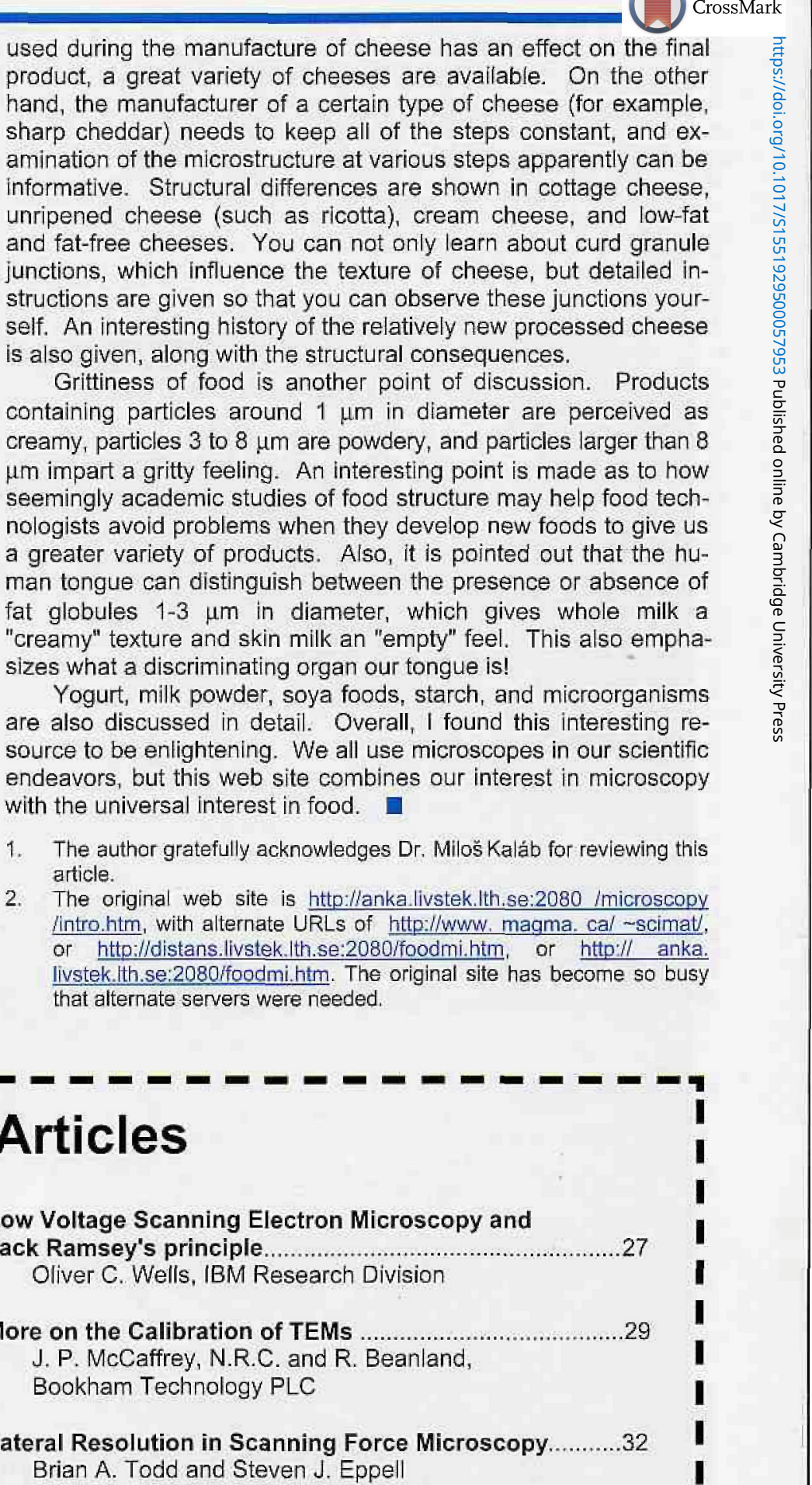

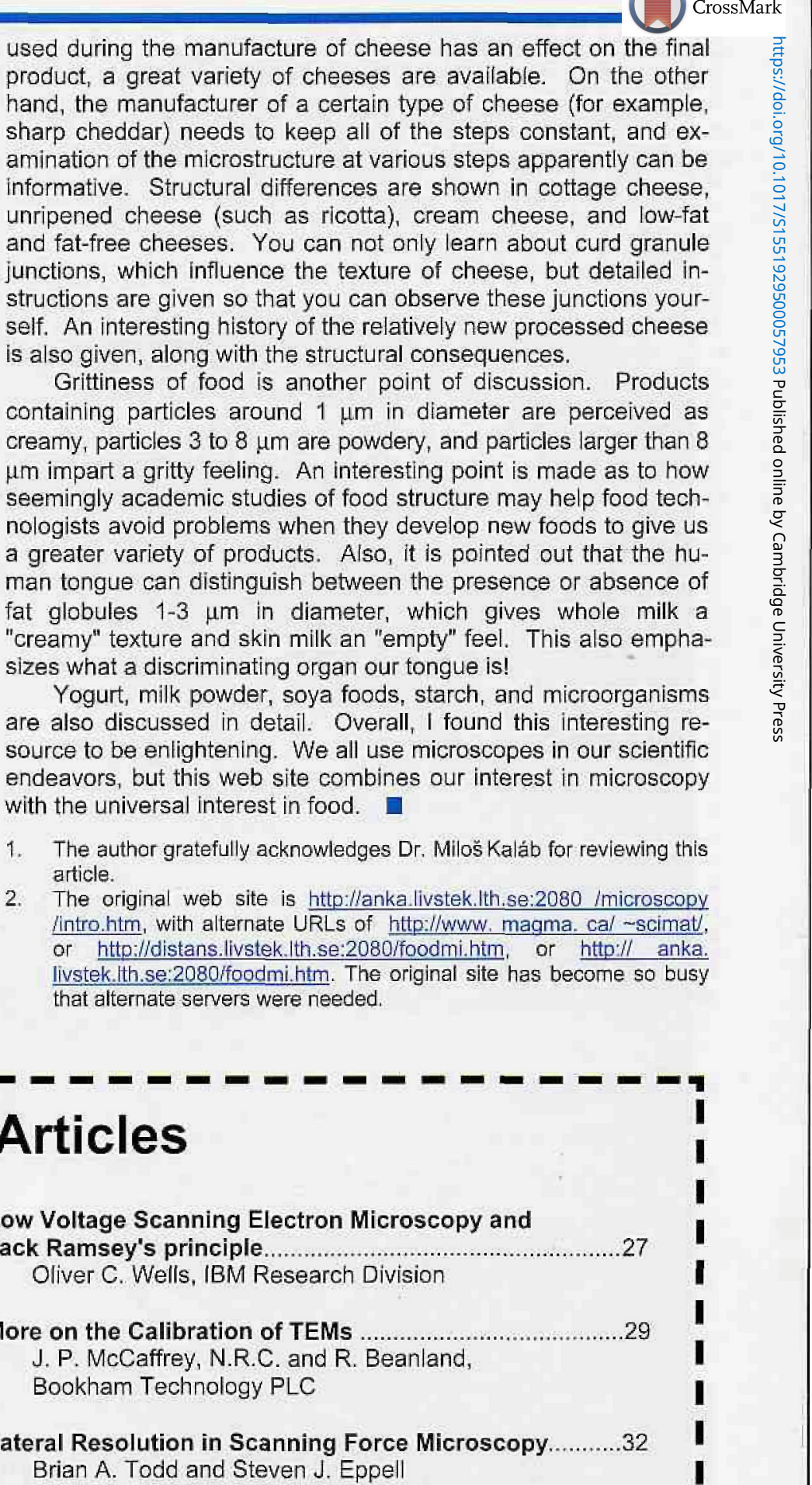

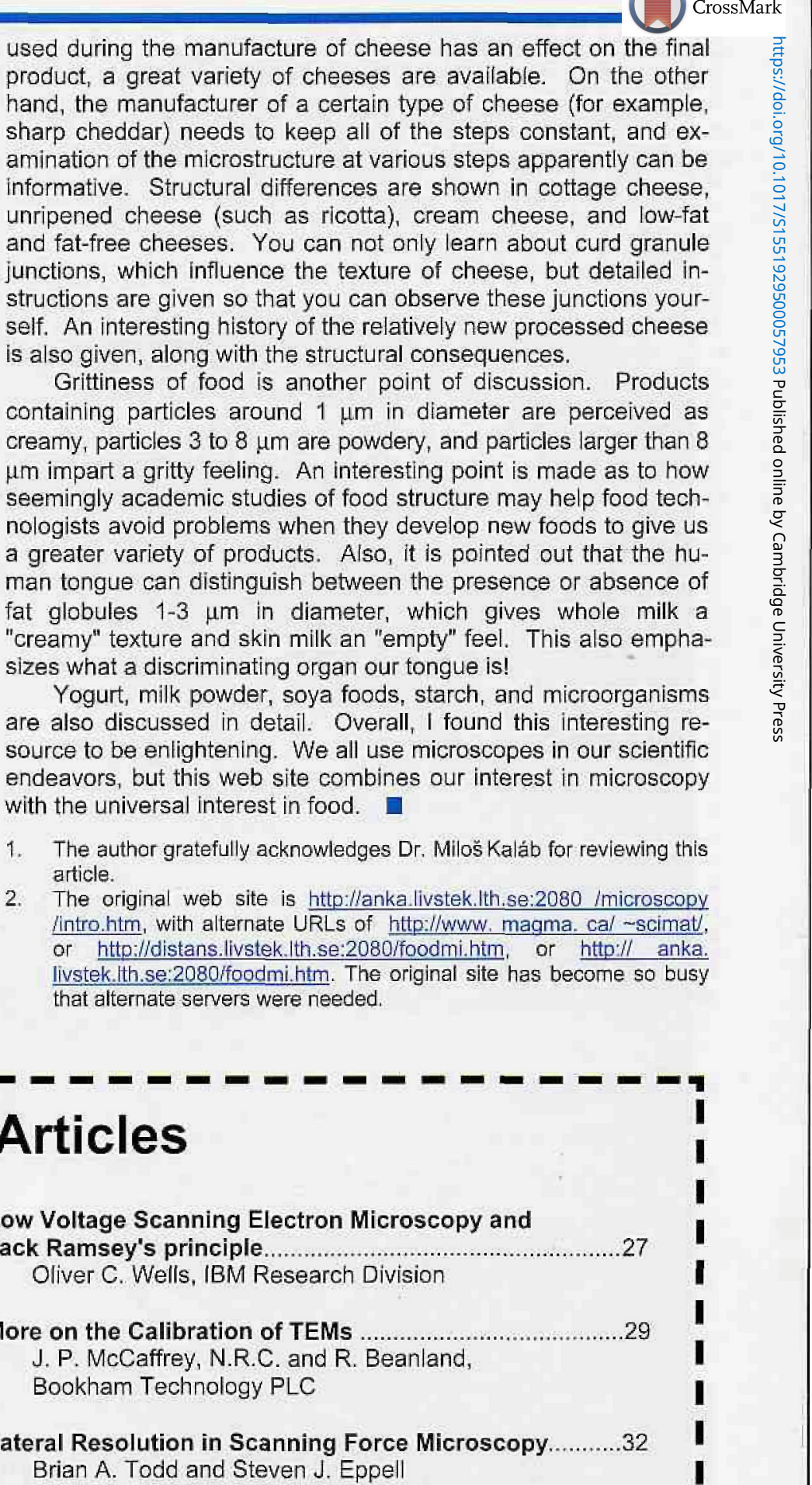

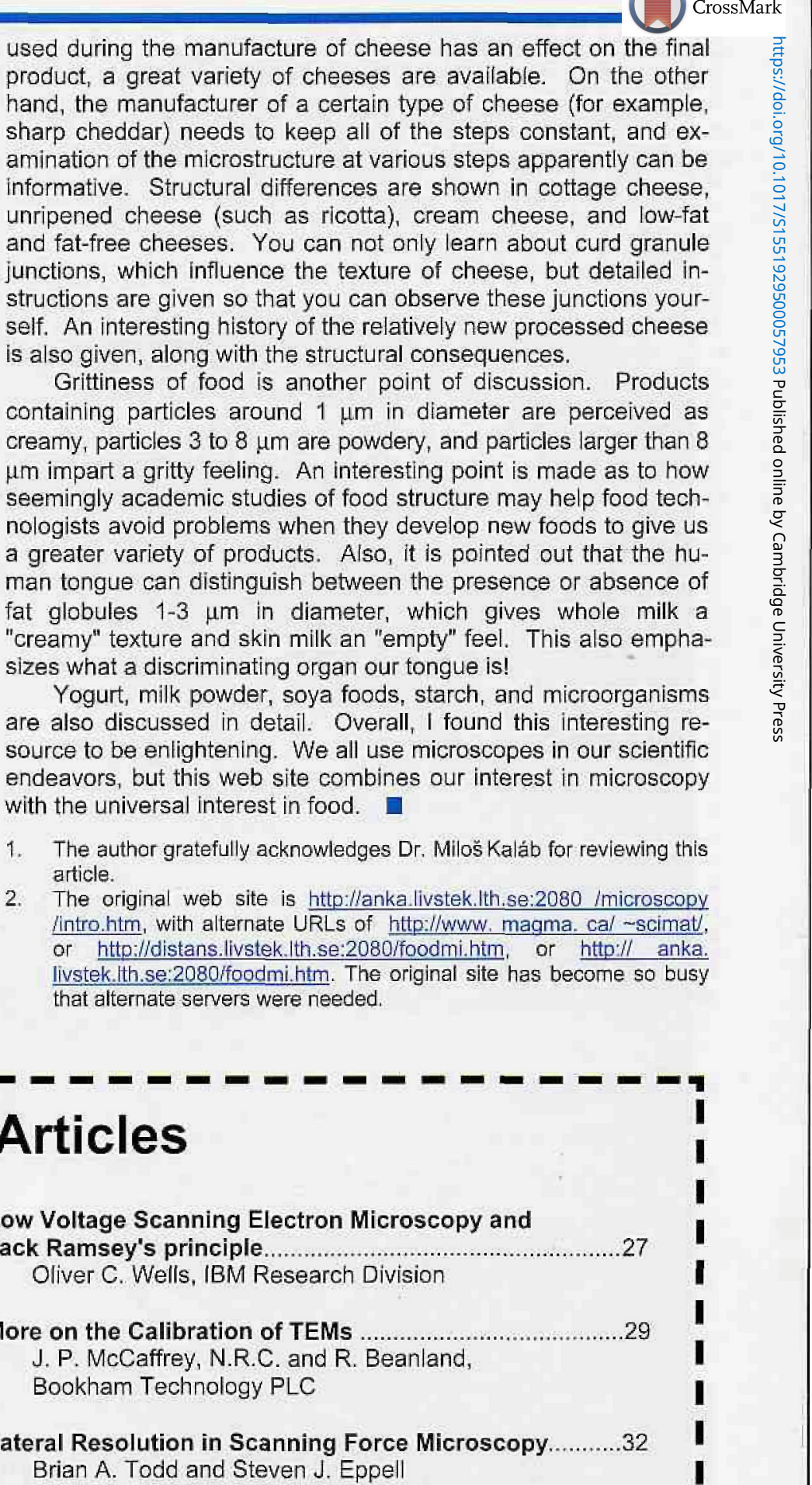

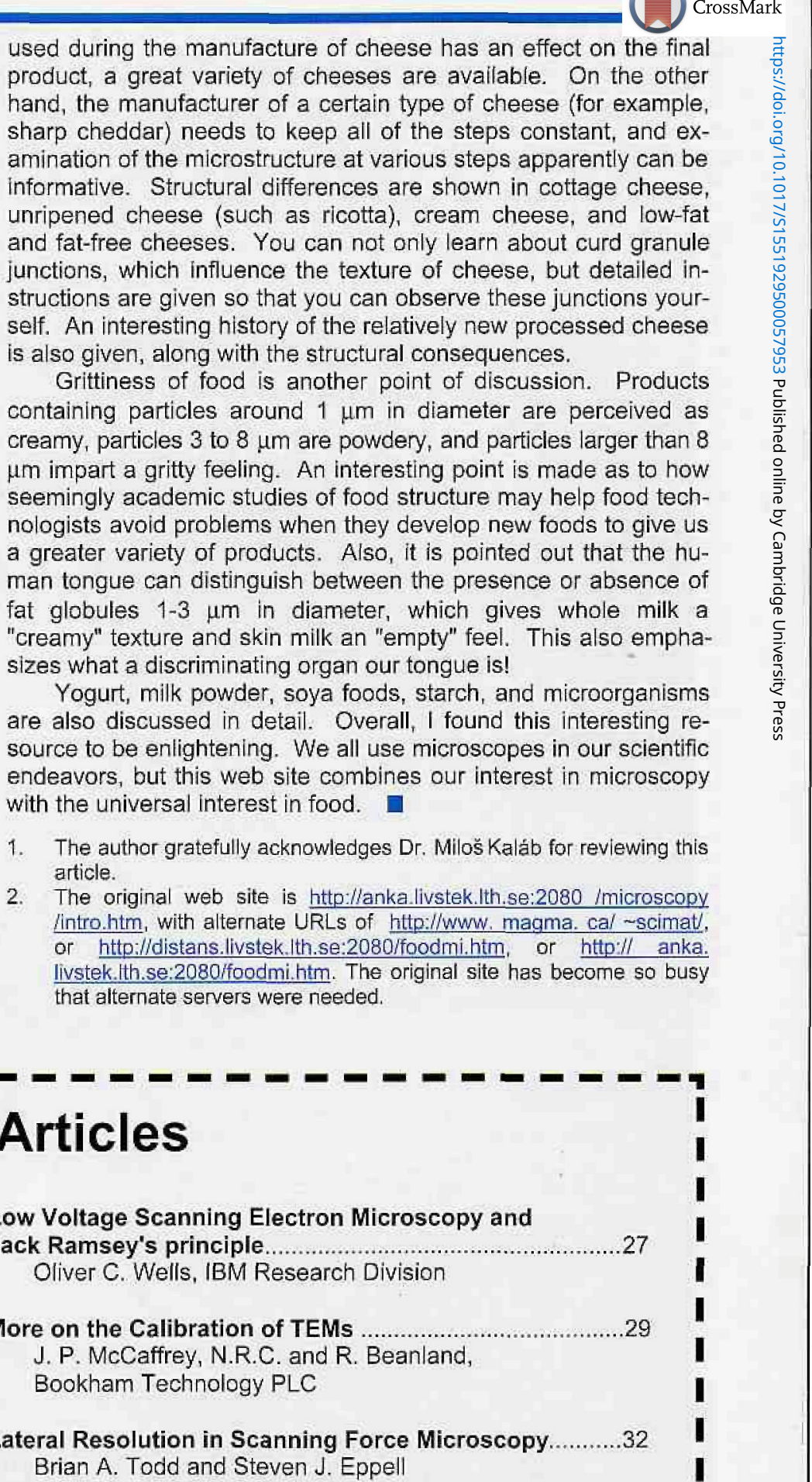

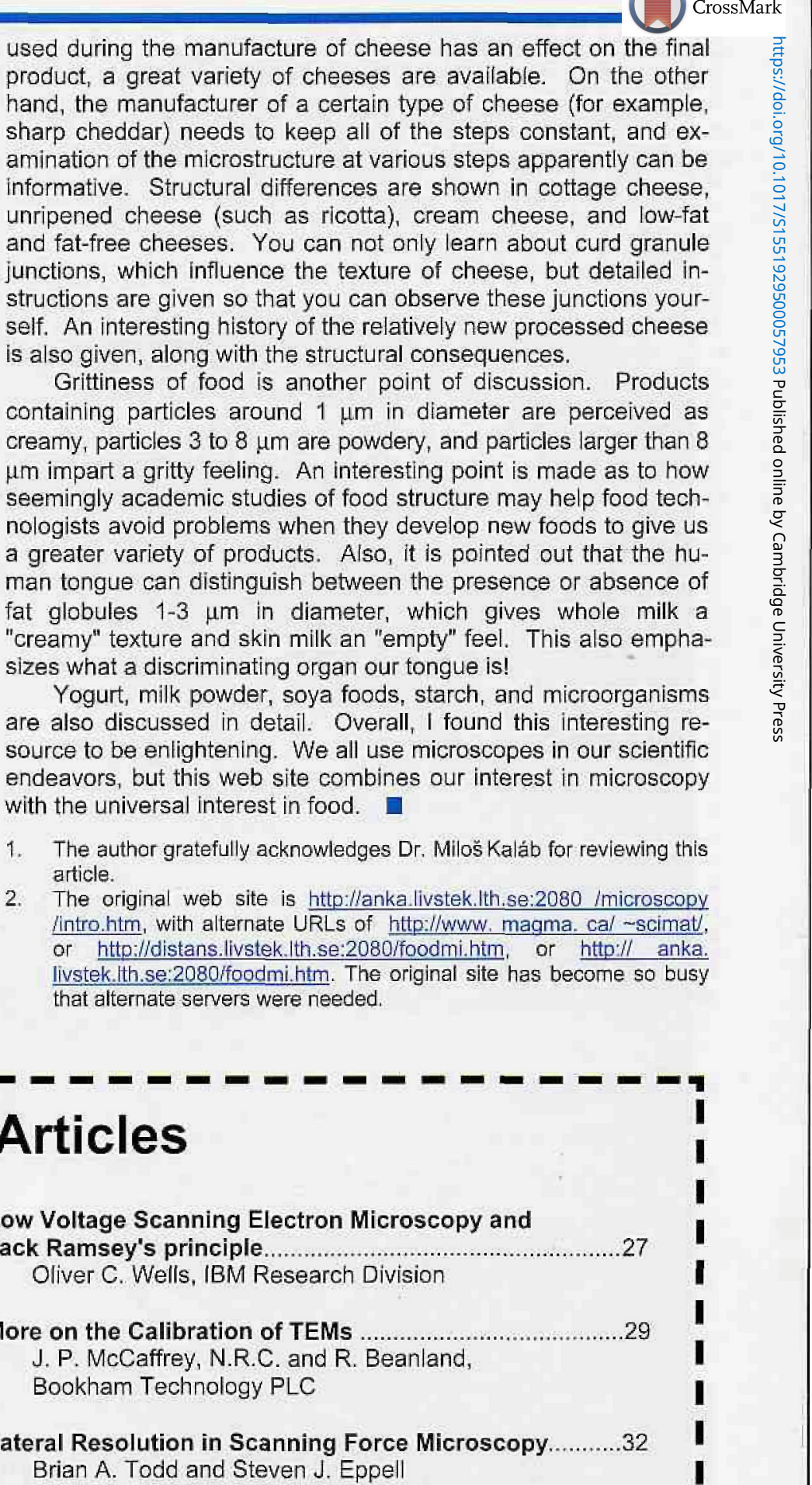

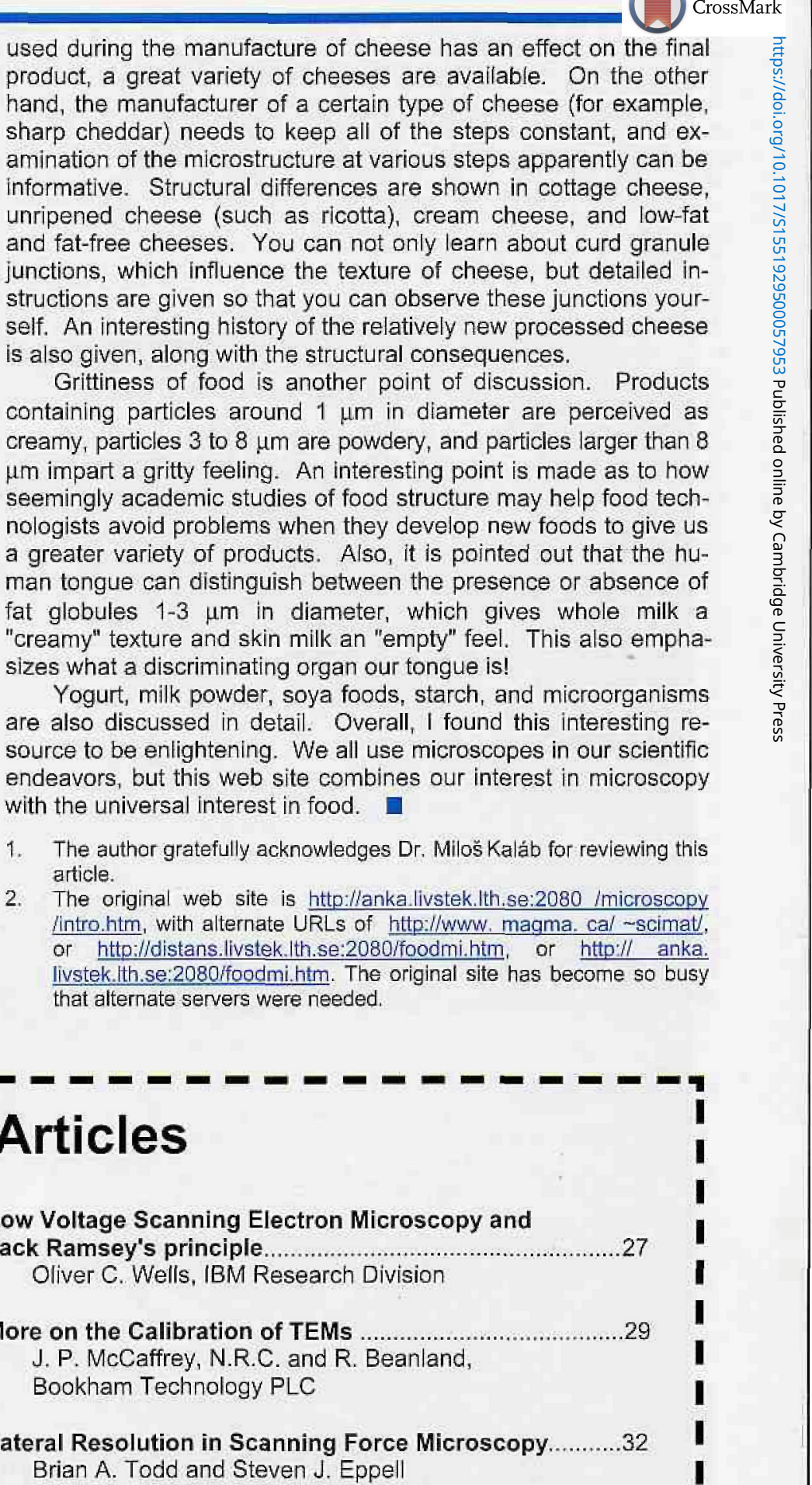

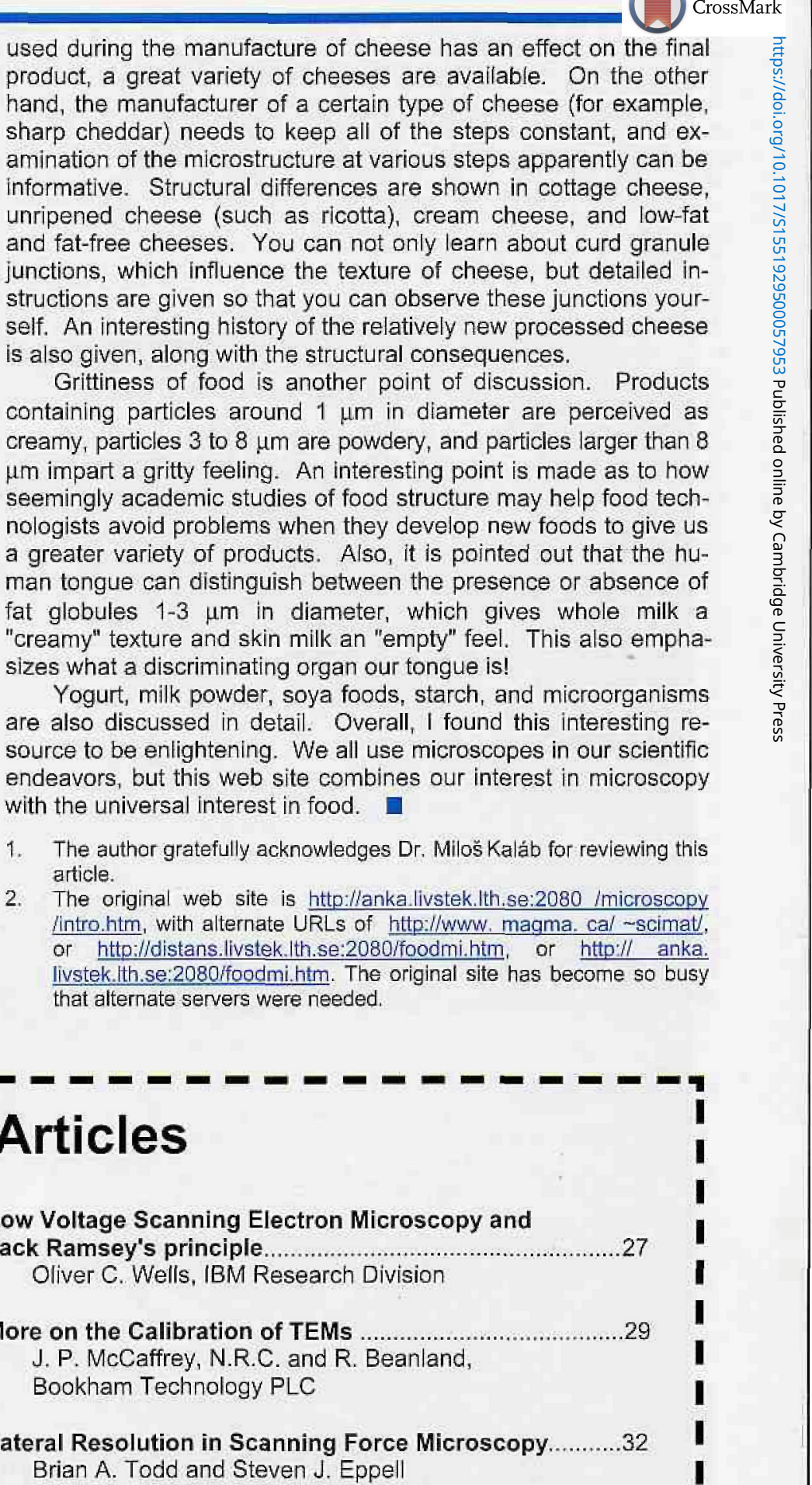

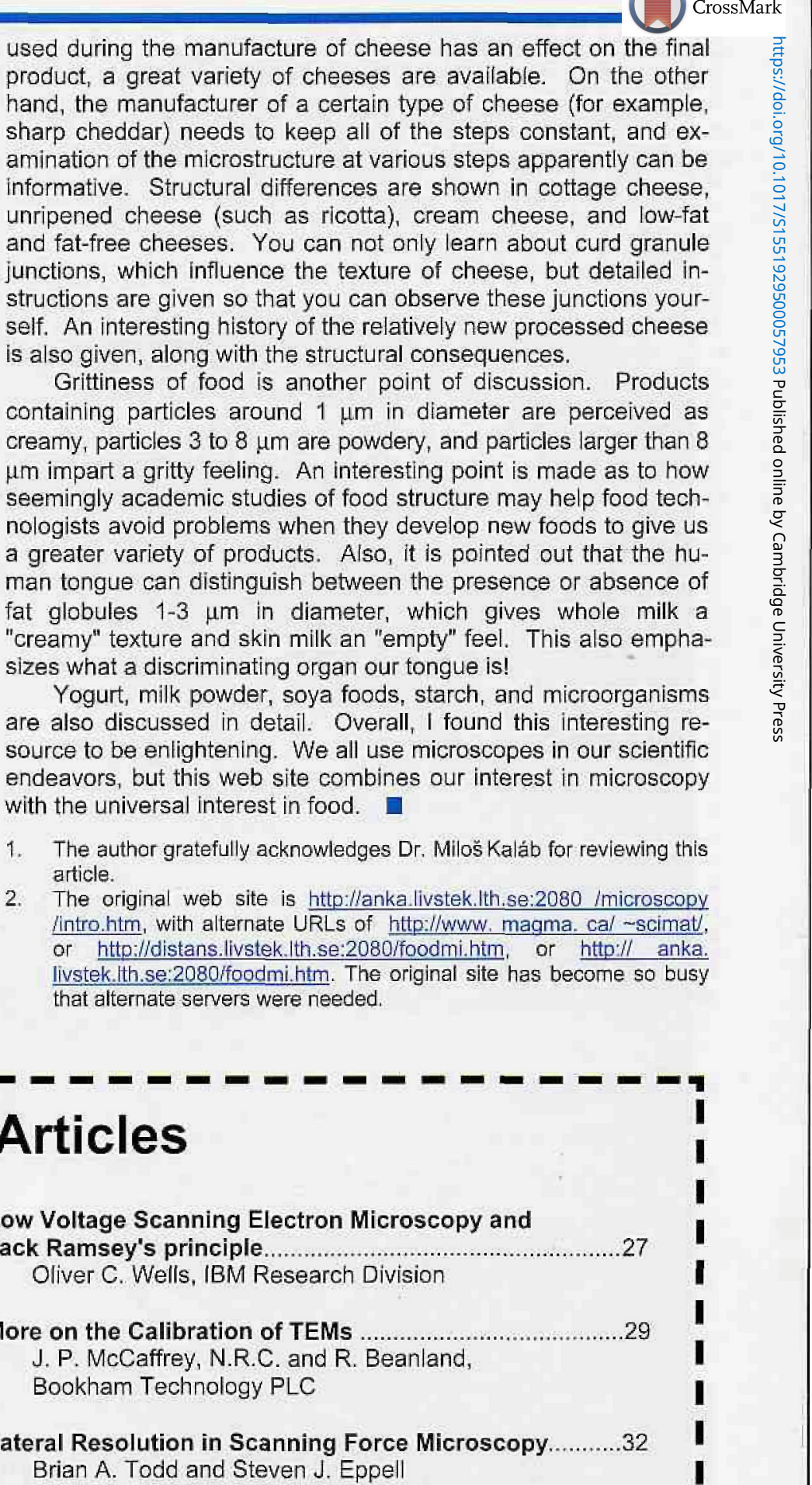

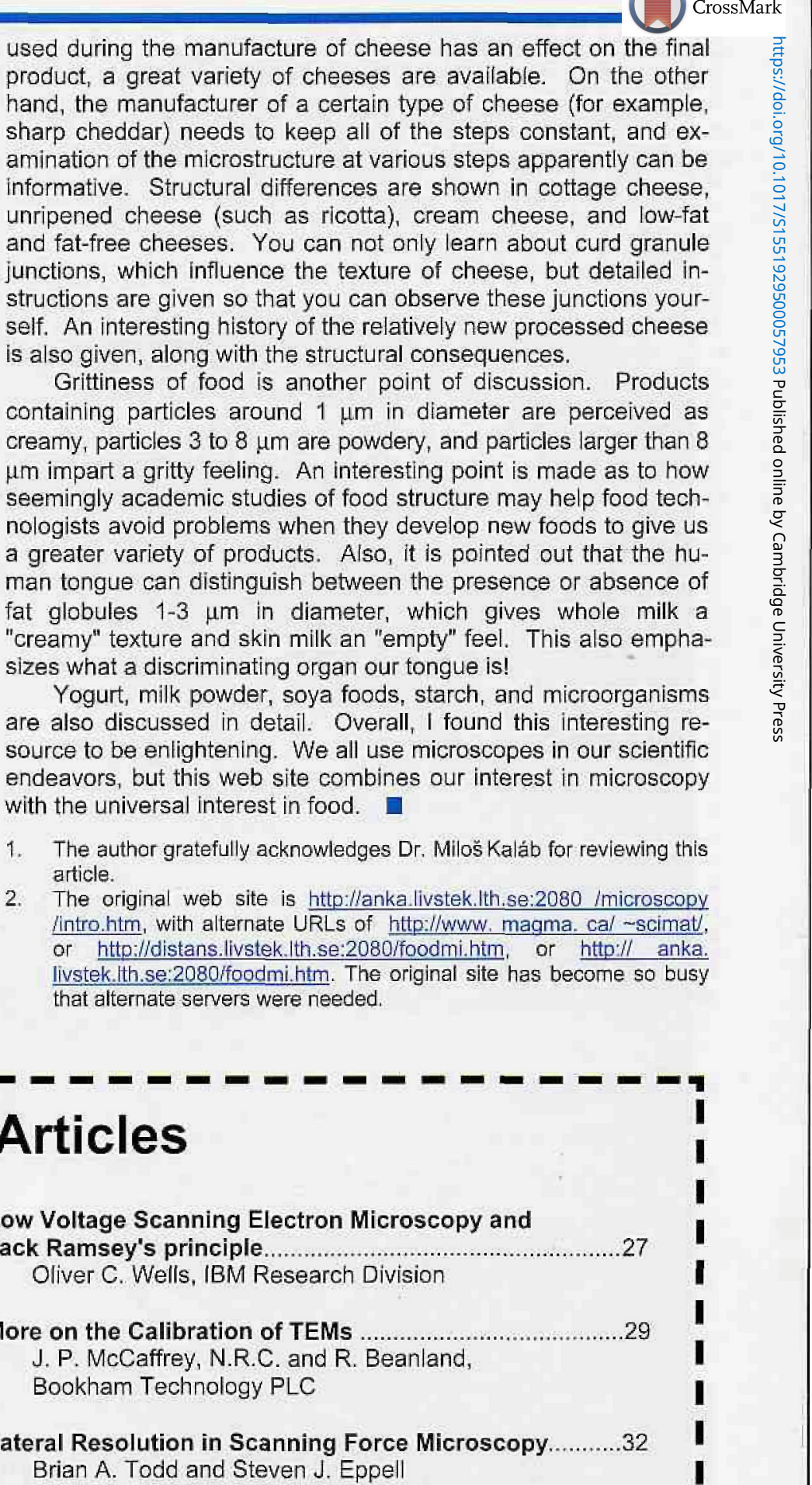

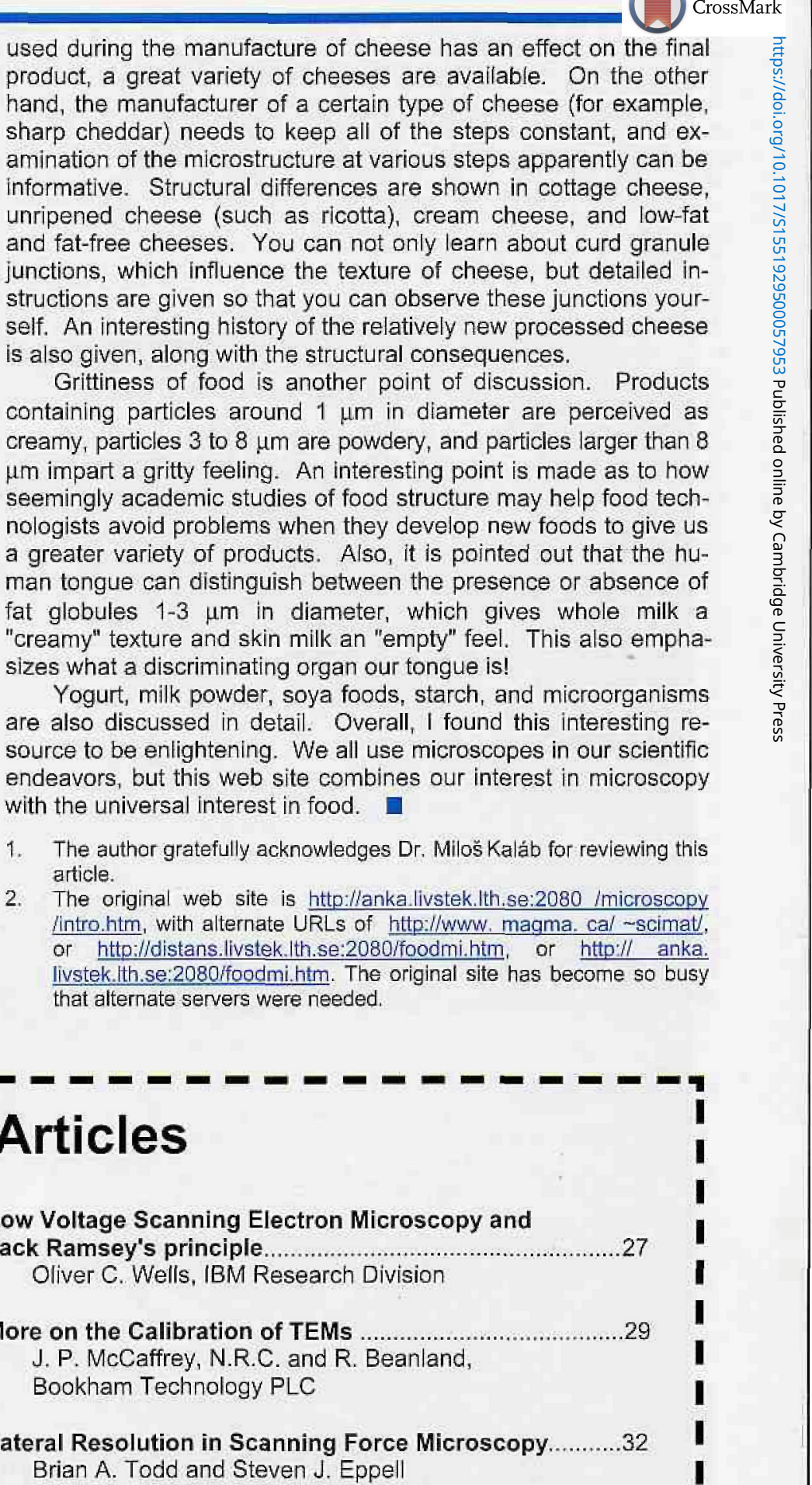

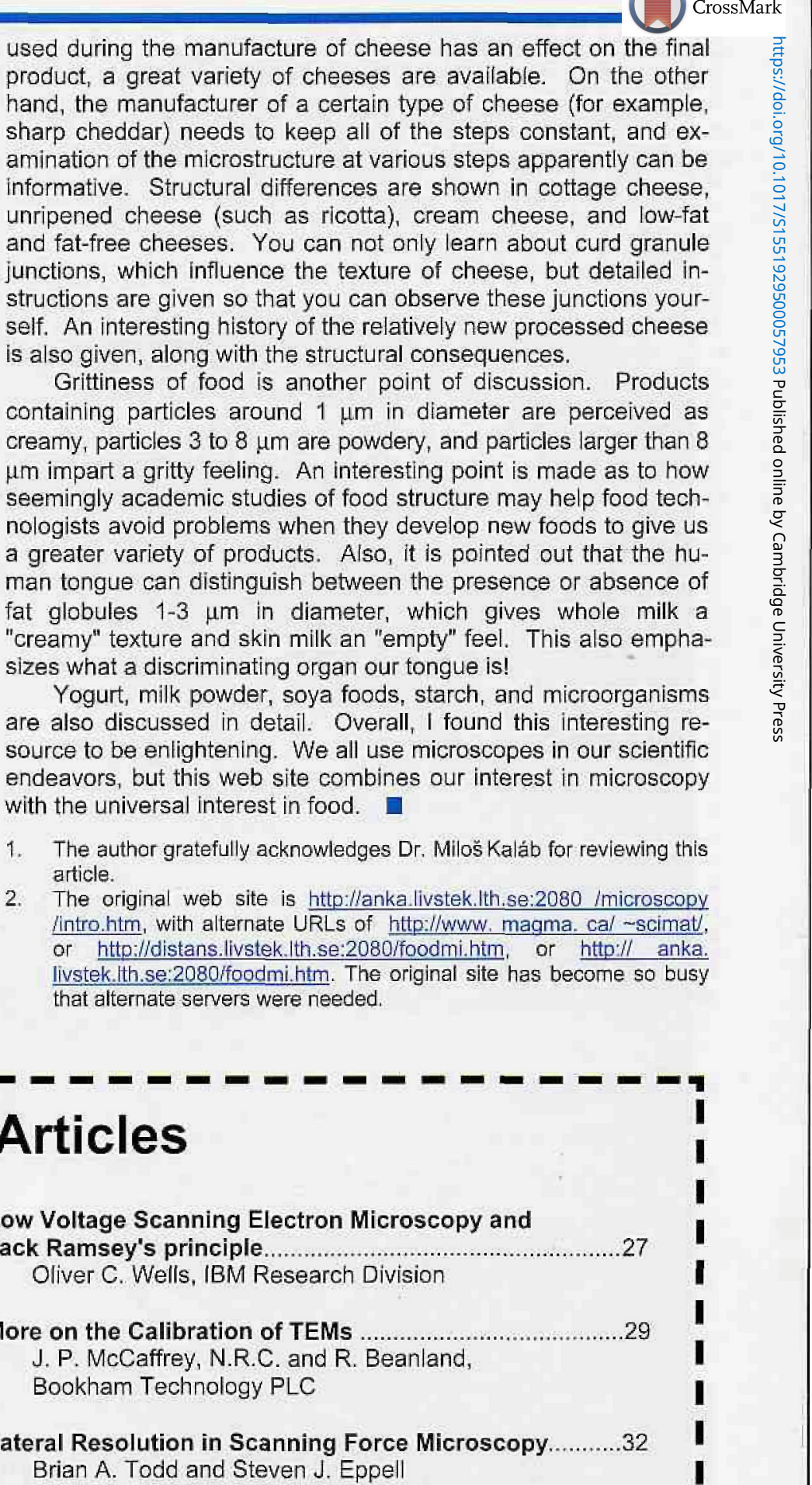

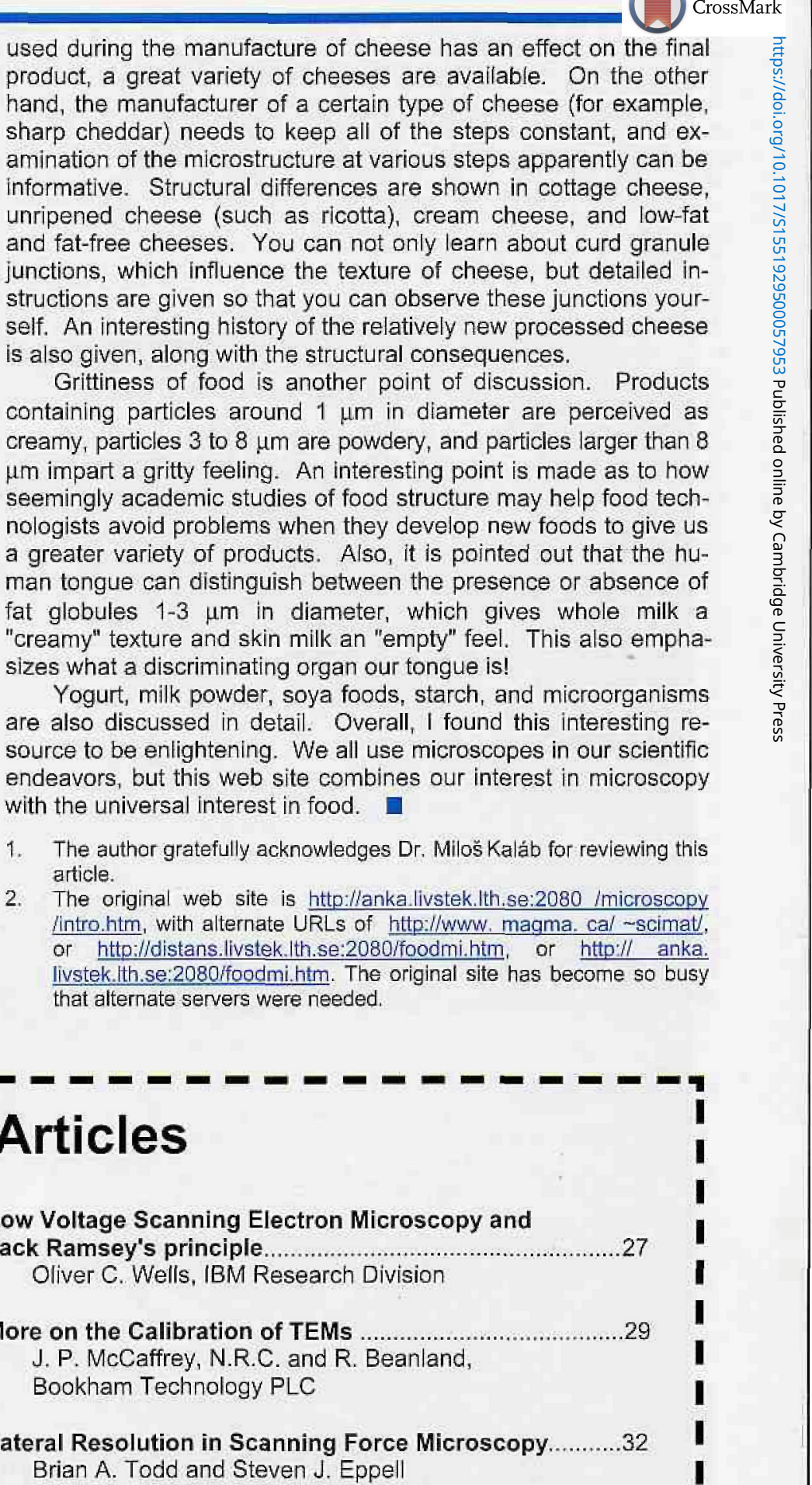

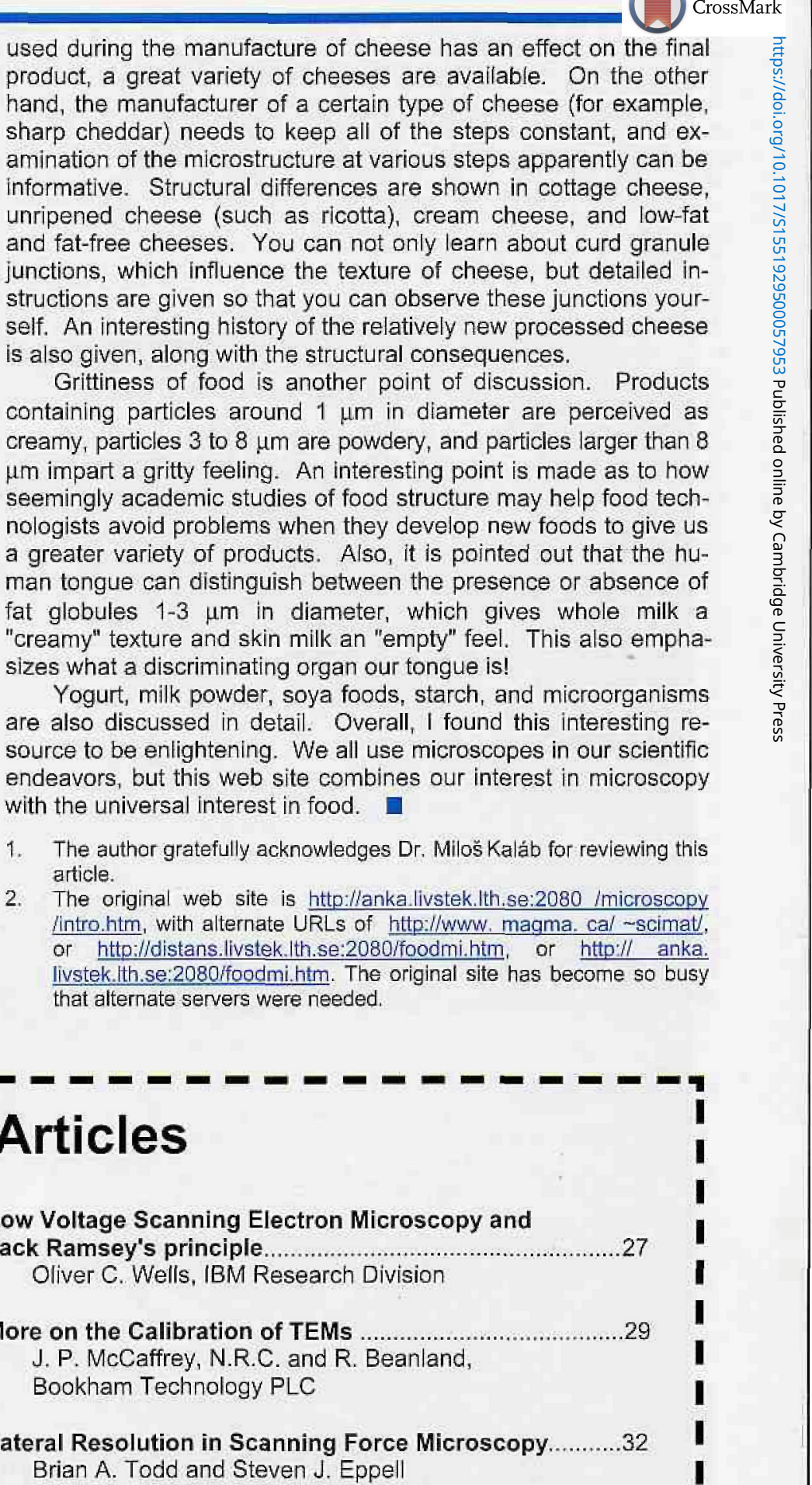

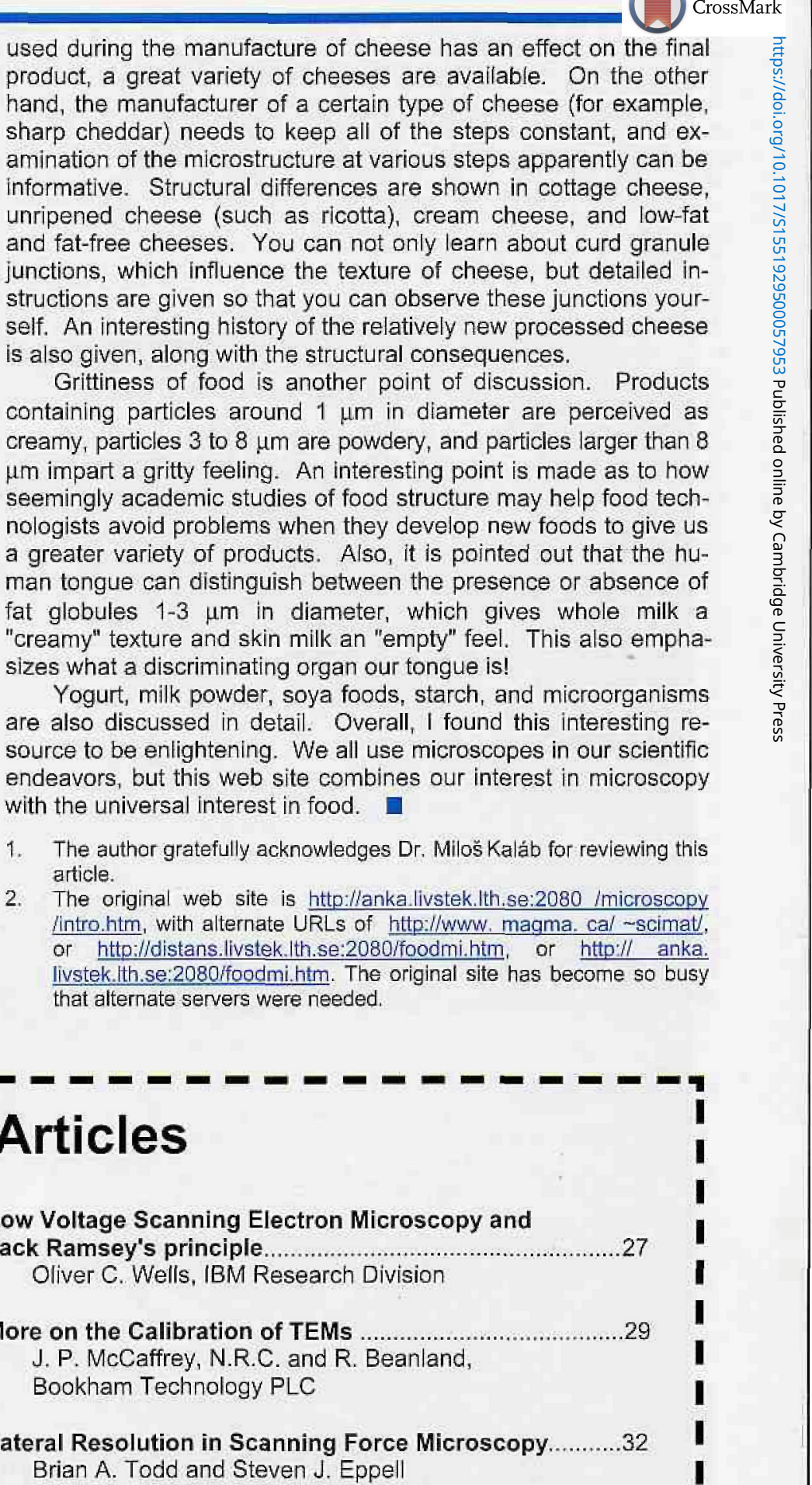

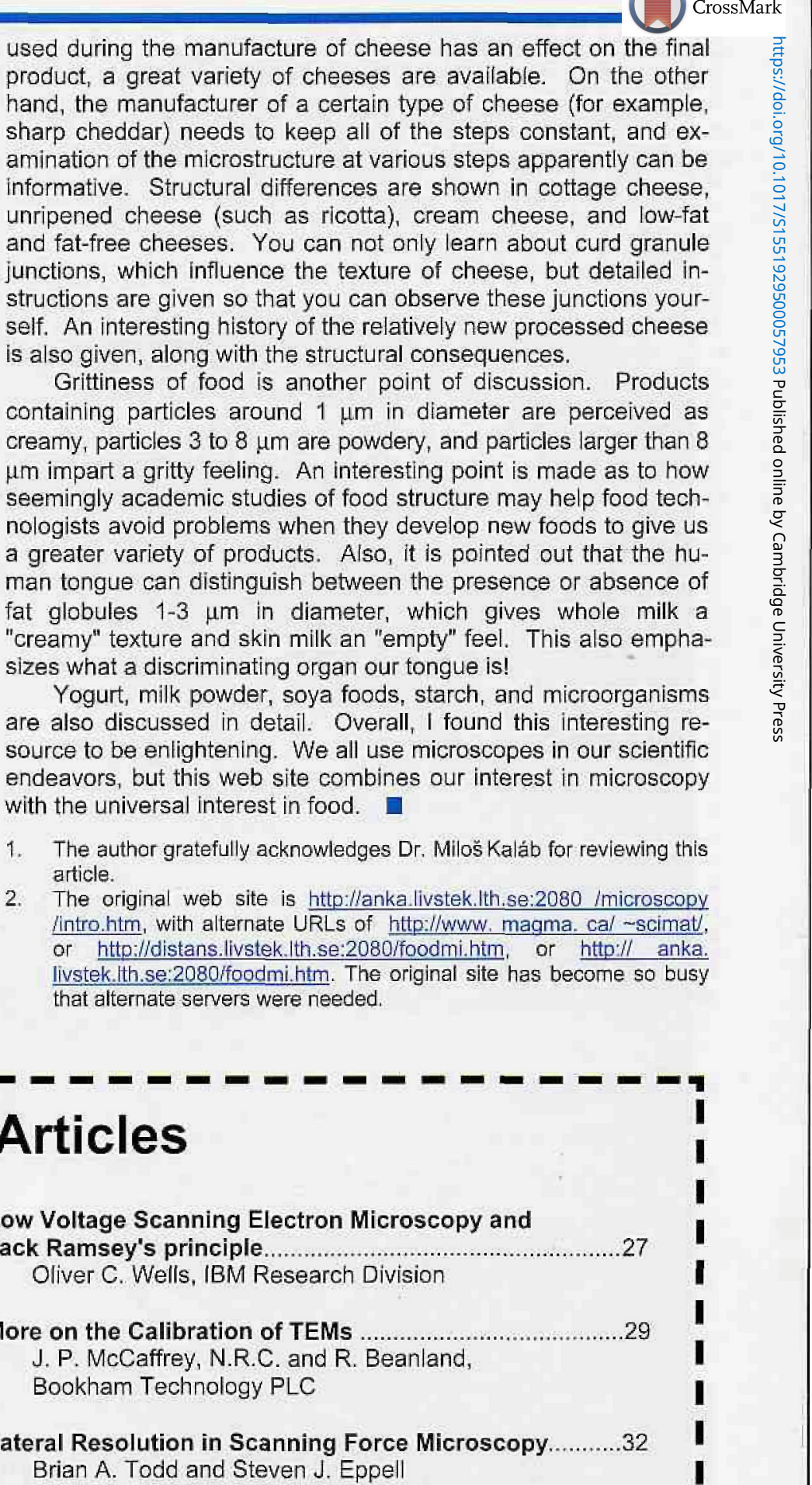

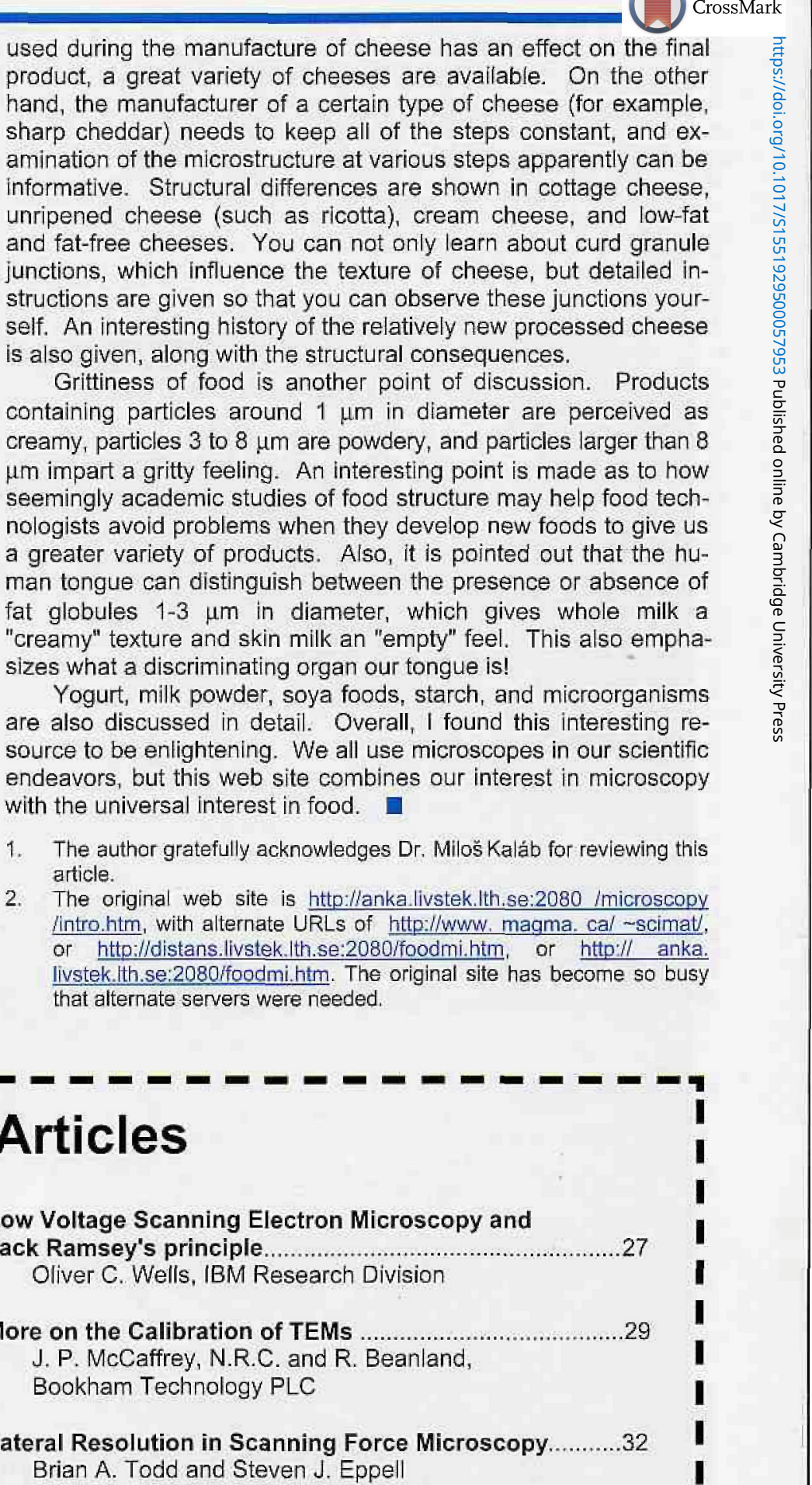

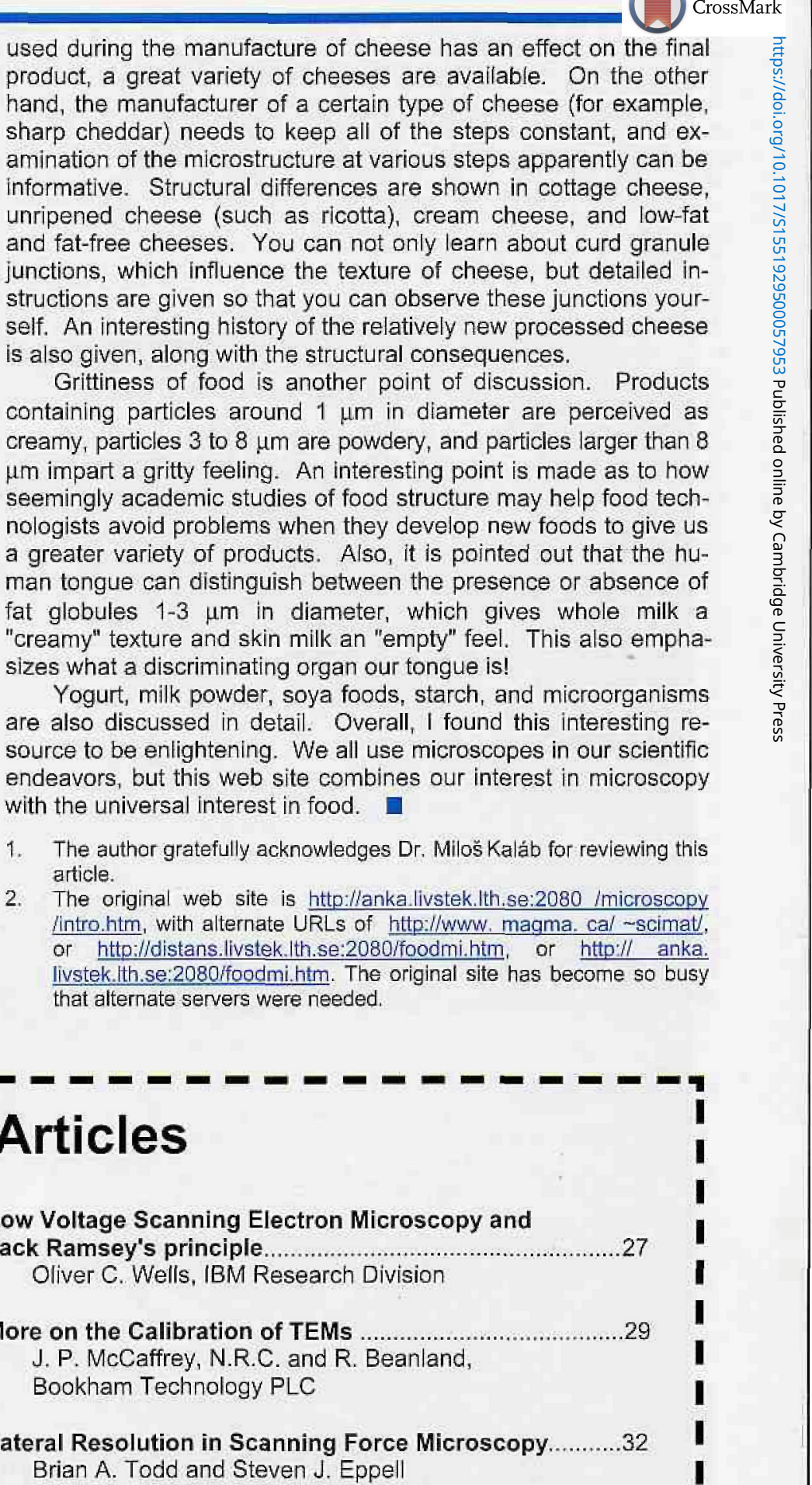

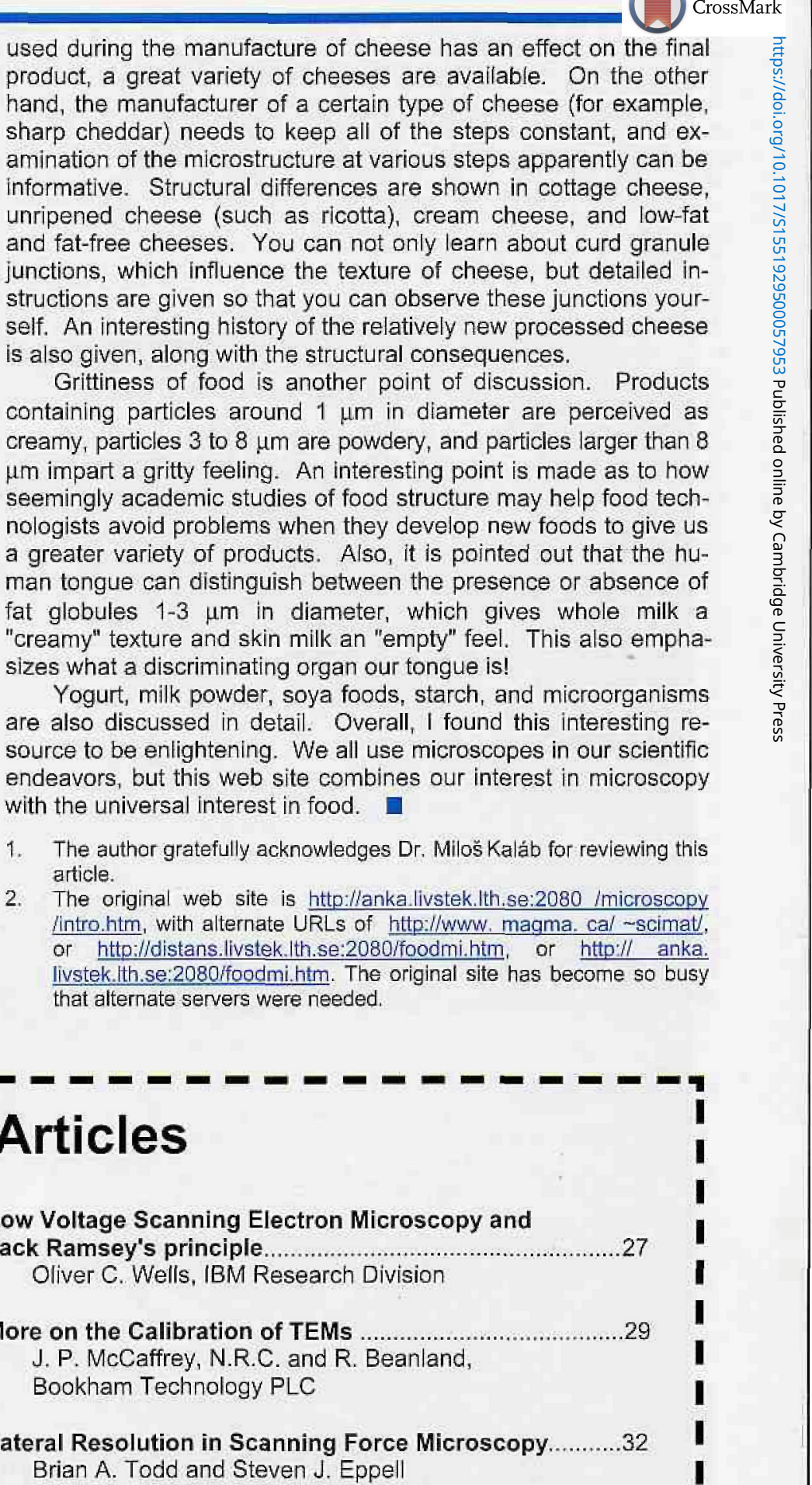

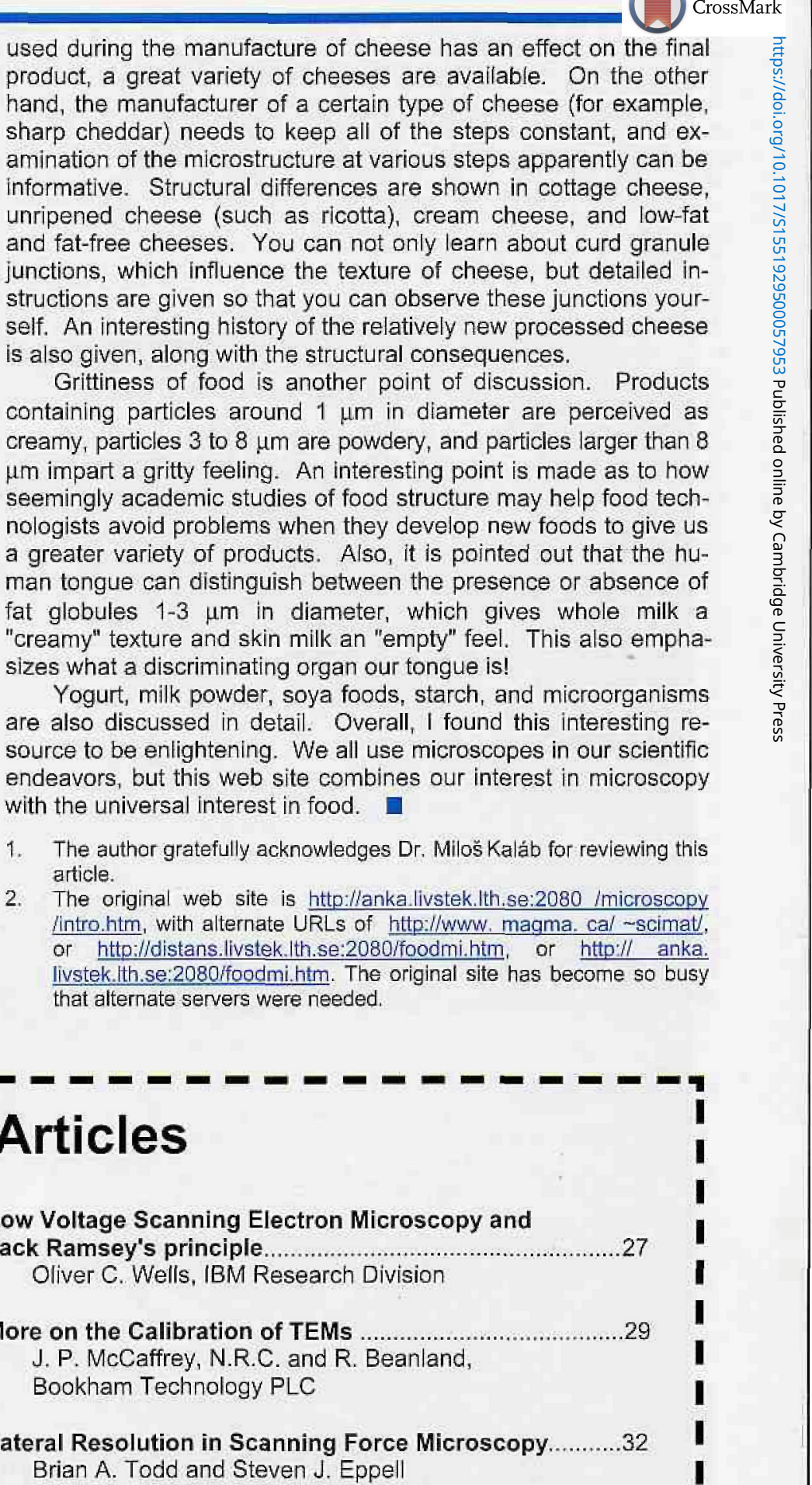

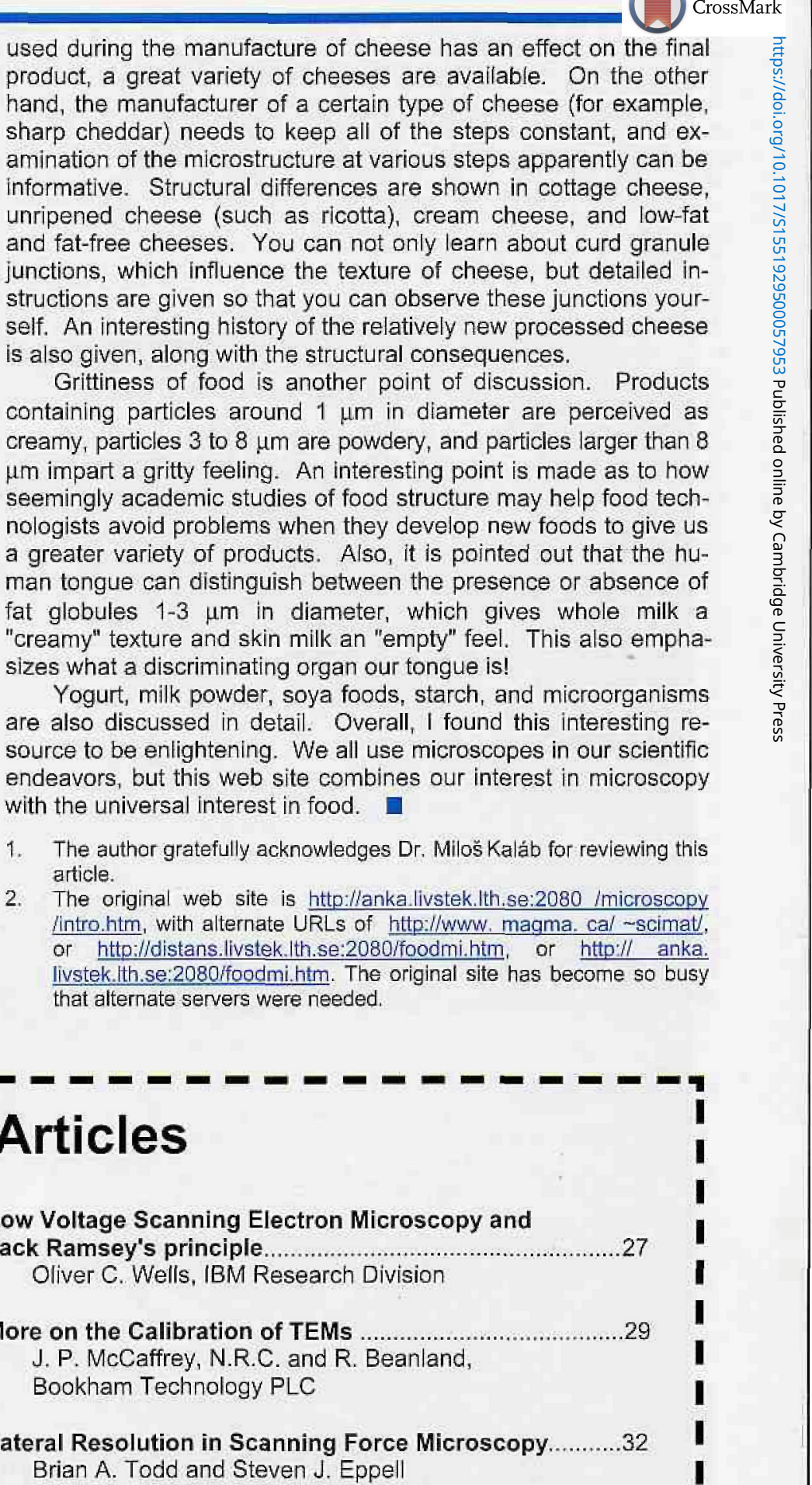

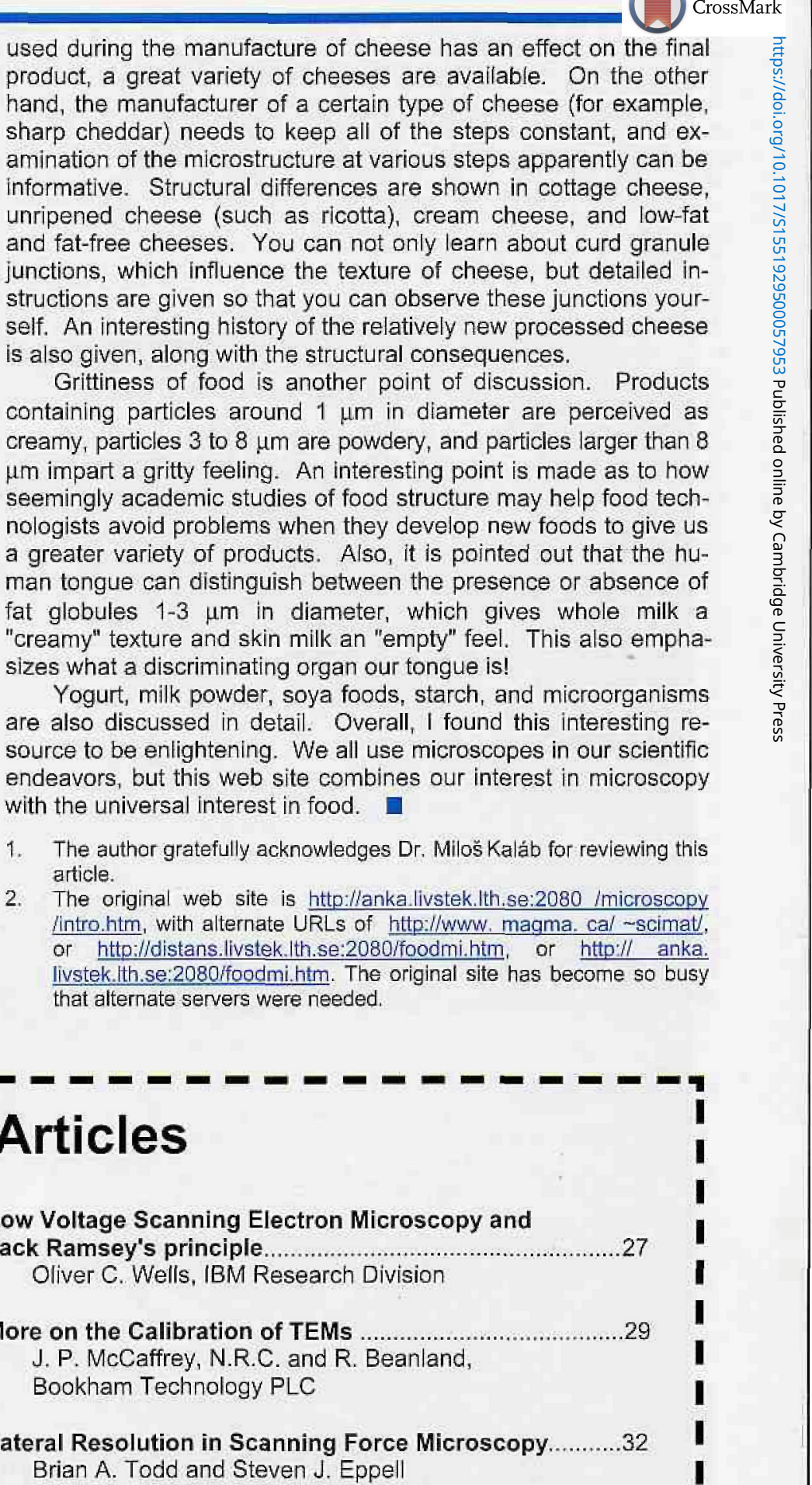

(1)
Brian A. Todd and Steven J. Eppell
Case Western Reserve University

Utilizing Original TEM Negatives and

Micrographs For Teaching in the Digital Domain..............33

Josè A. Mascorro, Tulane University

Plunge-Freezing into Slush Nitrogen..............................36

Philip Oshel, University of Wisconsin

Downloadable Photoshop Convolution Plug-In.................36

John Russ, North Carolina State University

A Home-made Antifade Medium for

Fluorescent Dyes

Tim Plummer, Mayo Clinic (1) 


\section{When $\mathrm{LN}_{2}$ is not practical}

\section{Introducing}

PGT Sahara SD Detector is quickly becoming the detector of choice for $\mathrm{X}$-ray applications requiring excellent energy resolution, high count rate capability and low energy sensitivity, ...without liquid nitrogen!

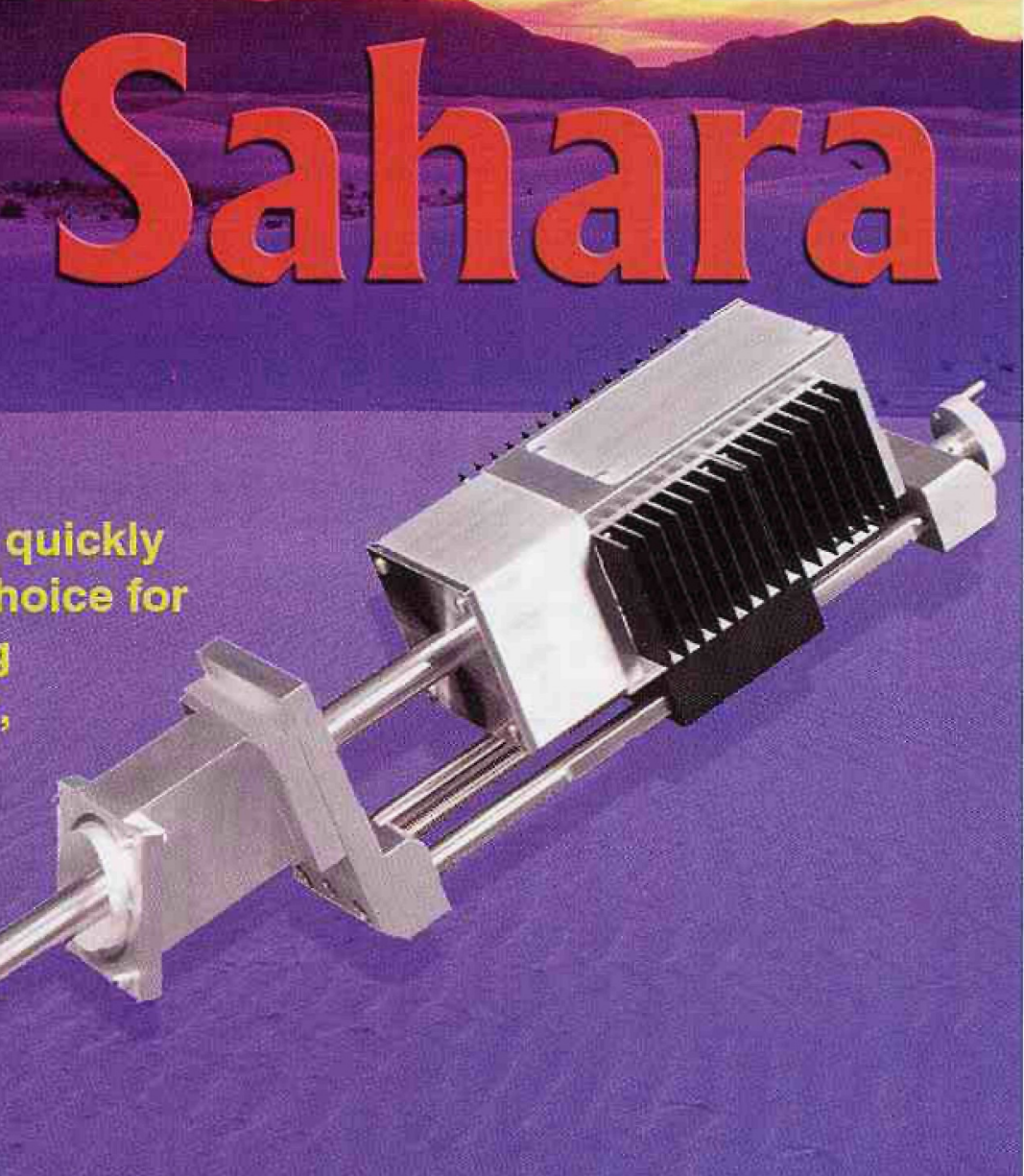

Excellent Energy Resolution

No liquid nitrogen, no water-cooling

No moving parts, or vibration

For more information visit our web site: www.pgt.com/sahara.html

Princeton Gamma-Tech, Inc. CN 863

Princeton, NJ 08542-0863

Web site: Www.pgt.com
Tel: (609) $924-7310$

Fax: (609) 924-1729

Toll free: $800-229-7484$

e-mail: sales@pgticom

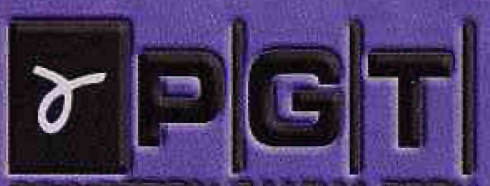

PEINEETUN EAMNA TEGA 


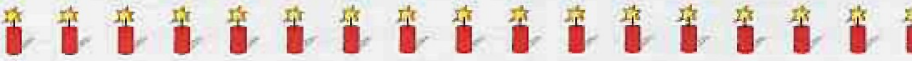 MSA Buys MICROSCOPY TODAY}

The Microscopy Society of America (MSA) is entering a new era in publication that will provide many new and exciting opportunities for our society. On April 1, 2002, MSA finalized the purchase of this magazine, Microscopy TODAY (MT), from Don Grimes. The acquisition of MT now provides MSA with two publications that will complement one another. The journal, "MICROSCOPY AND MICROANALYSIS," is the flagship academic publication of MSA and is edited by Charles Lyman. MT will be published in alternate months with our journal, and will be edited by Ron Anderson.

Why Did MSA Purchase MT?

MSA purchased MT to pursue a number of important goals, namely:

1) MT is well-recognized in the microscopy industry. Our new magazine will become an important vehicle for MSA's name recognition and will provide another means for MSA to carry out its mission of the promotion and advancement of the knowledge of the science and practice of microscopy, imaging, and analysis. MSA membership is not a requirement for receiving MT. We will continue to welcome subscriptions from everyone interested in any form of microscopy.

2) MT will also serve as a means for MSA to distribute valuable information and also the CALL FOR PAPERS for our annual meeting, MICROSCOPY \& MICROANALYSIS. The alternating publication of MT with our journal means that the CALL FOR PAPERS, which we will mail with the November issue of MT, will be in the hands of over 11,000 investigators by December of each year. This timely distribution will give those interested in submitting a paper at least two months to prepare and organize their paper prior to electronic submission by February 15.

3) The acquisition of MT provides MSA with an important new vehicle for growth of MSA membership and increased attendance at our annual meeting. Reaching out to interested sci-

entists and microscopists will be greatly enabled through marketing efforts in MT. The potential for growth by adding new members is extremely high when you realize that MT reaches nearly 8,000 workers in microscopy who are not now MSA members.

4) Improvement of our flagship journal, "MiCROSCOPY AND MICROANALYSIS," will now be possible. The long term goal will be to provide our journal editor with enough flexibility to improve the quality of the journal in a number of areas over the next several years. Journal departments like the "Meeting and Short Course Calendar," "Net Notes," etc., are already features of MT and properly belong solely there. We anticipate these changes will continue to raise the academic quality of our journal, making it the premiere microscopy publication in the world.

5) The style and composition of MT will change somewhat over the next year or two with new greater emphasis on imaging modalities as well as popular reviews on topics like PhotoShop, and its applications for improving images for publication. Our editor would be delighted to hear from all of you regarding those features of MT that you enjoy, and also to receive suggestions about new features you would like to see in the magazine. That said, we have no intention of making MT into a society newsletter like the MSA Bulletin (now discontinued). MT will remain pretty much the way it is now.

6) Finally, MT is expected to generate a new source of revenue in the future that will enable MSA to build up its reserves, and to help develop important MSA goals.

We hope everyone in the scientific community will continue to enjoy MT and we look forward to your input to our new editor.

Stan Erlandsen, MSA President 2002

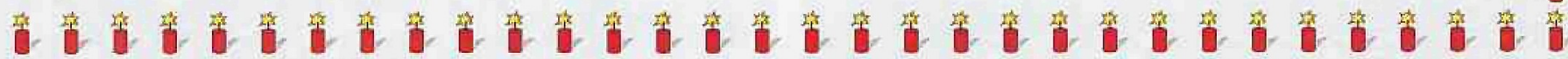

\section{JUST FOR FUN MICROGRAPH CONTEST}

At the upcoming Microscopy \& Microanalysis 2002 Conference in Quebec, (4/9 August 2001), we will repeat the popular "Just For Fun Micrograph Contest."

The concept of the contest is based upon composite images, each made up of two or more other images, at least one of which must be microscopical in nature. Contestants may enter up to two images each and do not have to be present at the M\&M Conference to win. Tasteful humor is appreciated.

Entries will be displayed in our booth and conference attendees will be invited to judge the entries and vote on the ones they consider to be the most "creative and interesting." First prize will be $\$ 300.00$ and the second and third prizes, respectively, will be $\$ 200.00$ and $\$ 100.00$. Winning entries may be featured as covers on future issues of MICROSCOPY TODAY.

While any reasonable size is acceptable; about $8^{\prime \prime} \times$ $11^{\prime \prime}$ is recommended. Entries should be hard copy, mounted on rather stiff background, suitable for posting. A $3^{\prime \prime} \times 5^{\prime \prime}$ card should accompany each entry-with an image description and the contributors name(s) and affiliation.

Entries are welcome from anyone interested in micros- copy: users, manufacturers/suppliers, students, kids, etc. Should you decide to enter our contest, it would be helpful if you let us know ahead of time (with the number of your entries) - just to make certain that we have enough room for everyone. E-mail is fine: (microtoday@attglobal.net) or by fax (845-463-4124).

We hope that you will decide to enter our contest!... Ron Anderson, Microscopy Today

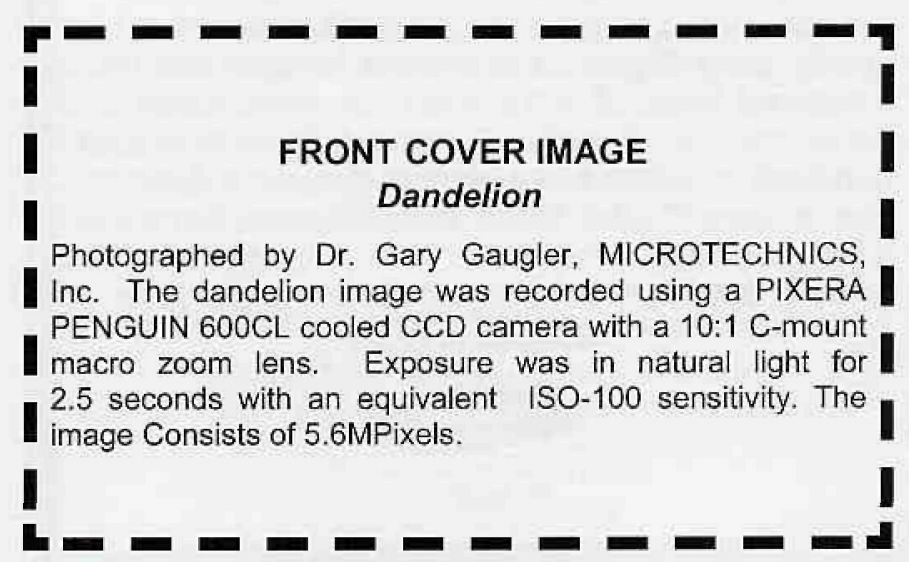

